San Jose State University

SJSU ScholarWorks

Master's Theses

Master's Theses and Graduate Research

1997

\title{
Cellular and humoral immune responses during chemotherapy with Diethylcarbamazine in human lymphatic filariasis
}

Suba Salahudeen

San Jose State University

Follow this and additional works at: https://scholarworks.sjsu.edu/etd_theses

\section{Recommended Citation}

Salahudeen, Suba, "Cellular and humoral immune responses during chemotherapy with

Diethylcarbamazine in human lymphatic filariasis" (1997). Master's Theses. 1595.

DOI: https://doi.org/10.31979/etd.w2ac-qr6g

https://scholarworks.sjsu.edu/etd_theses/1595

This Thesis is brought to you for free and open access by the Master's Theses and Graduate Research at SJSU ScholarWorks. It has been accepted for inclusion in Master's Theses by an authorized administrator of SJSU

ScholarWorks. For more information, please contact scholarworks@sjsu.edu. 


\section{INFORMATION TO USERS}

This manuscript has been reproduced from the microfilm master. UMI films the text directly from the original or copy submitted. Thus, some thesis and dissertation copies are in typewriter face, while others may be from any type of computer printer.

The quality of this reproduction is dependent upon the quality of the copy submitted. Broken or indistinct print, colored or poor quality illustrations and photographs, print bleedthrough, substandard margins, and improper alignment can adversely affect reproduction.

In the unlikely event that the author did not send UMI a complete manuscript and there are missing pages, these will be noted. Also, if unauthorized copyright material had to be removed, a note will indicate the deletion.

Oversize materials (e.g., maps, drawings, charts) are reproduced by sectioning the original, beginning at the upper left-hand comer and continuing from left to right in equal sections with small overlaps. Each original is also photographed in one exposure and is included in reduced form at the back of the book.

Photographs included in the original manuscript have been reproduced xerographically in this copy. Higher quality 6" $\times 9$ 9" black and white photographic prints are available for any photographs or illustrations appearing in this copy for an additional charge. Contact UMI directly to order.

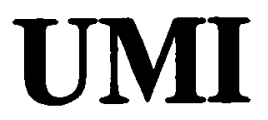

A Bell \& Howell Information Company 
. 


\title{
CELLULAR AND HUMORAL IMMUNE RESPONSES DURING CHEMOTHERAPY WITH DIETHYLCARBAMAZINE IN HUMAN LYMPHATIC FILARIASIS
}

\author{
A Thesis \\ Presented to \\ The Faculty of the Department of Biological Sciences \\ San Jose State University \\ In Partial Fulfillment \\ of the Requirements for the Degree \\ Master of Science
}

by

Suba Salahudeen

December, 1997 
OMI Number: 1388213

UMI Microform 1388213

Copyright 1998, by UMI Company. All rights reserved.

This microform edition is protected against unauthorized copying under Title 17, United States Code.

\section{UMI \\ 300 North Zeeb Road \\ Ann Arbor, MI 48103}




\section{() 1997}

Suba Salahudeen

\section{ALL RIGHTS RESERVED}




\title{
APPROVED FOR THE DEPARTMENT OF BIOLOGICAL SCIENCES
}

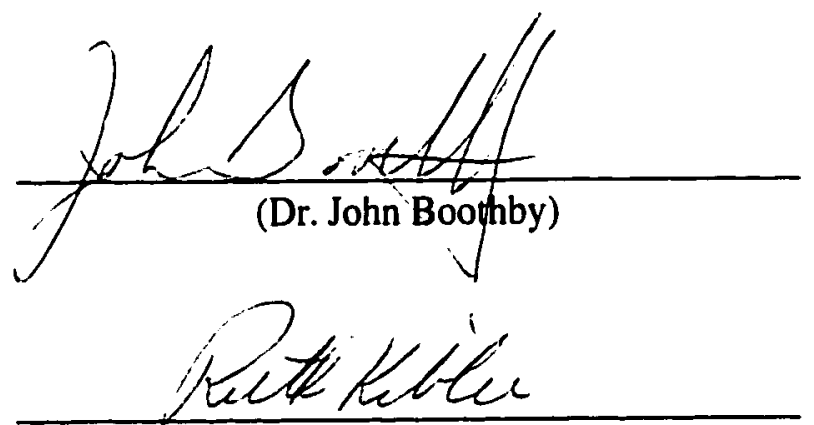

(Dr. Ruth Kibler)

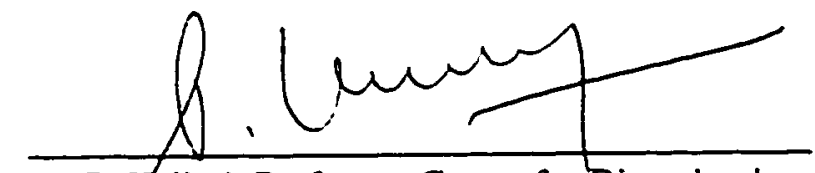

(Dr. P. Kaliraj, Professor, Centre for Biotechnology, Anna University, Chennai, India)

\author{
APPROVED FOR THE UNIVERSITY
}




\title{
ABSTRACT \\ CELLULAR AND HUMORAL IMMUNE RESPONSES DURING CHEMOTHERAPY WITH DIETHYLCARBAMAZINE IN HUMAN LYMPHATIC FILARIASIS
}

\author{
by Suba Salahudeen
}

A study was undertaken to examine the changes in the cellular and humoral immune responses during treatment with the microfilaricidal drug, Diethylcarbamazine (DEC) in asymptomatic microfilaraemics with active filarial infection. The levels of circulating antigens and circulating neutrophil and eosinophil numbers were also compared before and at frequent intervals during the 14 days of chemotherapy with DEC. When compared to pre-treatment levels, no significant changes were observed in circulating antigens and Brugia malayi adult worm (BmA) antigen specific antibodies during DEC treatment. $\mathrm{BmA}$ induced lymphoproliferative responses improved significantly on day one of chemotherapy. The expresion of IL-2 and IL-10 cytokine genes increased significantly on day 7 compared to pre-treatment levels. The numbers of circulating neutrophils and eosinophils also increased significantly after start of DEC therapy. The increased production of $\mathbb{L - 2}$ and increase in BmA driven lymphoproliferation suggested that chemotherapy with DEC modulated the cell-mediated immune responses during the treatment period. 


\section{ACKNOWLEDGEMENTS}

I thank Dr. Kunthala Jayaraman, Dean of Technology, Anna University, for her encouragement and for giving me an opportunity to complete my research at the Centre for Biotechnology, Anna University, Chennai-25, India.

I specially thank Dr. John T. Boothby, my Graduate Advisor at San Jose State University without whose approval I could not have done this work. I thank Dr. Ruth Kibler, member of my committee, for her prompt and thorough editing of my thesis. Dr. Boothby and Dr. Kibler were very patient in helping me with the corrections.

I also thank Dr. P. Kaliraj, Director, Centre for Biotechnology, Anna University, and Dr. R.B. Narayanan, Professor, for their support and suggestions from time to time.

I sincerely acknowledge the help by my senior colleagues Mr. M. Ravichandran and Ms. P. Lalitha. I also take this opportunity to thank the technical staff at this Centre for their invaluable help and assistance. Thanks are due to the Filarial Officer, Dr. Ragunathan and members of his team, National Filarial Control Unit, Chennai for providing the samples for study.

This work was carried out by the funding provided by Indo-U.S. Project PL480 on Filariasis sanctioned through the Helminthology Division, Laboratory for Parasitic Diseases, National Institute of Health, Bethesda, MD, USA to the Centre for Biotechnology, Anna University, Chennai. I express my sincere thanks for granting me fellowship throughout the period of my work.

I extend my special thanks to my family who gave me constant encouragement and mental support throughout the period of work. 


\section{TABLE OF CONTENTS}

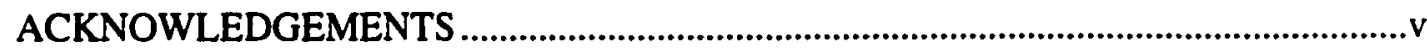

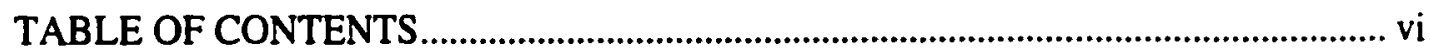

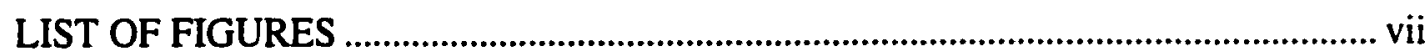

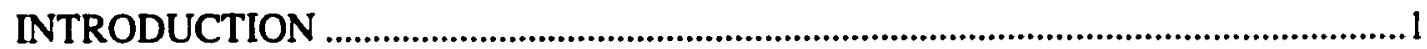

Map showing global prevalence of filarial infections..........................................................2

Diagrammatic representation of the life cycle of filarial parasites .......................................4

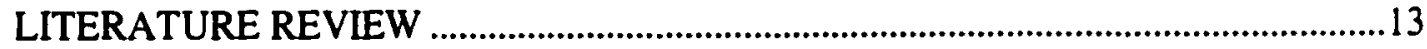

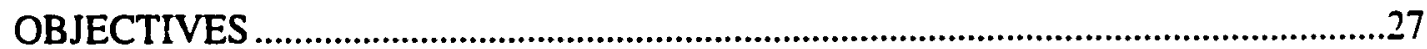

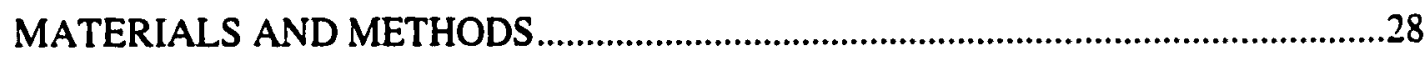

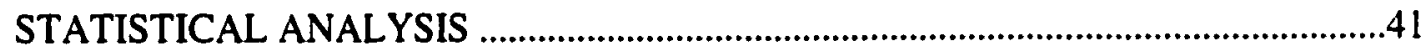

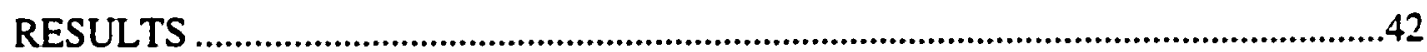

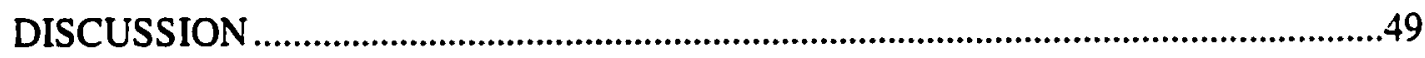

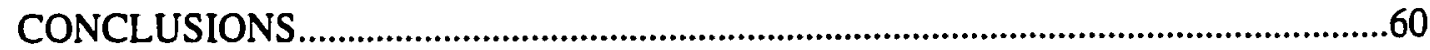

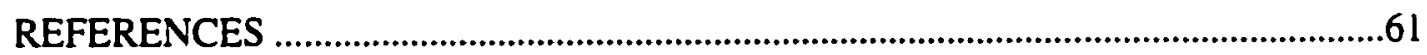

APPENDIX I (cDNA sequence of Interleukin-2) ..........................................................

APPENDIX II (cDNA sequence of Interleukin-10) ......................................................73 


\section{LIST OF FIGURES}

Figure Number ...................................................................................................Page

Figure 1 PBMC proliferative response of EN, MF, and CP to BmA and PHA..............42

Figure 2 a Mean \pm SEM values of microfilarial counts $/ \mathrm{ml}$..............................................43

Figure $2 \mathrm{~b}$ Mean \pm SEM levels of circulating antigens ......................................................43

Figure 3 Effect of DEC on PBMC proliferative response to BmA in MFs....................44

Figure 4 a Unstimulated Control and BmA stimulated expression of HPRT, IL-2, and IL-10 genes seen pre and on day 7 during DEC chemotherapy.......................45

Figure $4 \mathrm{~b}$ Graph showing HPRT normalized mean OD values of $\mathbb{L}-2$ and IL-10..........46

Figure 5 a Mean \pm SEM values of BmA specific isotype antibodies .................................46

Figure $5 \mathrm{~b}$ Mean \pm SEM values of BmA specific IgM and IgE.......................................47

Figure 6 Mean absolute count + SEM of Neutrophils, Eosinophils and Lymphocytes....48 


\section{INTRODUCTION}

Human lymphatic filariasis is caused by three species of lymphatic dwelling, arthropod borne nematodes: Wuchereria bancrofti, Brugia malayi, and Brugia timori. They are classified in the family Onchoceridae, super family Filarioidea. While the filarial infections caused by $W$. bancrofti are transmitted by the mosquito Culex quinquefasciatus, the anophelines and mansonioides are the vectors for transmission of Brugian filariasis. World-wide, filariasis causes the highest clinical morbidity and is the second leading cause of permanent and long-term disability among other infectious diseases. In human lymphatic filariasis, patients suffer from repetitive attacks of lymphangitis, lymphadenitis with filarial fevers; from lymphatic obstruction resulting in lymph oedema, hydrocoele and chyluria; and, in rare instances, from tropical pulmonary eosinophilia (TPE), which results from pulmonary obstructive and restrictive symptoms. Infection with these parasites may cause acute or chronic obstruction of the lymphatics that may ultimately lead to elephantiasis. The disease is an impediment to socioeconomic development in 73 endemic countries of the tropics and sub-tropics.

In India at least 381 million people are exposed to the risk of infection, 25 million are carriers of microfilaria and 19 million have chronic disease. In India, all states and union territories except Jammu and Kashmir, Himachal Pradesh, Punjab, Haryana, Chandigarh, Delhi, Rajasthan, Nagaland, Manipur, Meghalaya, Tripura, Arunachal Pradesh, Mizoram and Sikkim are endemic for bancroftian filariasis (Dhanda et al., 1996). In India the 
distribution of filariasis caused by $B$. malayi is mostly found in Kerala, but scattered foci of low prevalence are reported in Orissa, Assam, Madhya Pradesh, Andhra Pradesh and Tamil Nadu. Infections with B. timori are not seen in India. Globally, infections with $W$. bancrofti are prevalent in Central Africa, South America, Southern China, and are widely distributed in the tropics. B. malayi infection is restricted to Indonesia, the Malay peninsula, Vietnam, Southern China, and Sri Lanka. B. timori infection is restricted to the Indonesian islands of Timor and Flores (Denham and McGreevy, 1977).

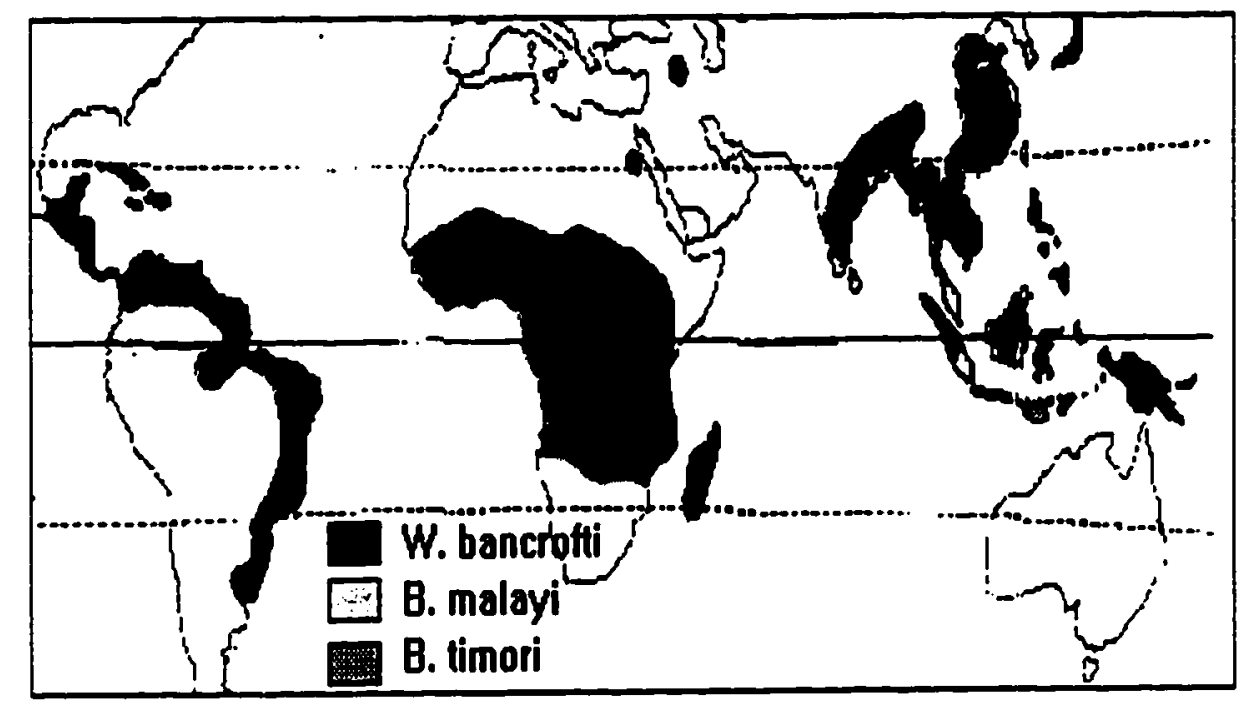

Map showing global prevalence of filarial infections

\section{LIFE CYCLE}

The life cycle of the filarial parasite includes both a definitive human host and the intermediate host, the mosquito. Adult male and female worms of $W$. bancrofti and $B$. malayi inhabit primarily the lumen of lymphatics where they may live for 7 to 10 years, 
although cases of 40 year longevity have also been reported (Leeuwin et al., 1962). The sexually mature adult worm is the largest of all stages. It is long and slender with blunt ends. Male worms vary from 20 to $40 \mathrm{~mm}$ in length in W. bancrofti and B. malayi while the female worms are 60 and $100 \mathrm{~mm}$ in length respectively. Adult females are ovoviviparous, producing thousands of microfilariae or first-stage larvae (L1) after fertilization. The microfilariae of $W$. bancrofti and $B$. malayi retain the egg membrane as a sheath. The microfilariae migrate from the lymphatics to the peripheral blood circulation and may number in the millions in infected persons. The microfilariae do not undergo further development in humans and can survive for 1 to 2 years (Eberhard and Lammiee, 1991).

Several species of microfilariae exhibit marked periodicity depending on their number or concentration in peripheral circulation (Nanduri and Kazura, 1989). The nocturnally periodic microfilariae of $W$. bancrofti and $B$. malayi have peak concentrations in peripheral circulation between 2200 and $0200 \mathrm{~h}$. Few, if any, microfilariae are detectable in the circulation during day light hours.

This microfilarial parasite stage is ingested by the mosquitoes along with the blood meal. The larvae reach the thoracic musculature or fatty tissues of the mosquitoes where they shorten by metamorphosis into sausage-shaped bodies of 240 to $250 \mu \mathrm{m}$ in length. At this stage of development (L2), the first true moult occurs after which the tail portion atrophies and the intestinal tract of the heiminth becomes well defined. A second moult follows and the infective larvae at this stage (L3) are slender and measure 1.4 to $2.0 \mathrm{~mm}$ 
in length. The period of time from ingestion of microfilariae to maturation into the infective larvae is 10 to 14 days. These third-stage larvae move to the labium or proboscis sheath of the mosquito and infect a new host when the mosquito feeds. They enter the skin through the wound made by the mosquito, moult to fourth-stage larvae (L4) and eventually develop into sexually mature adult worms. The prepatent period (the time from infection to detection of microfilariae released by the adult female worms) is approximately one year for these human filarial parasites.

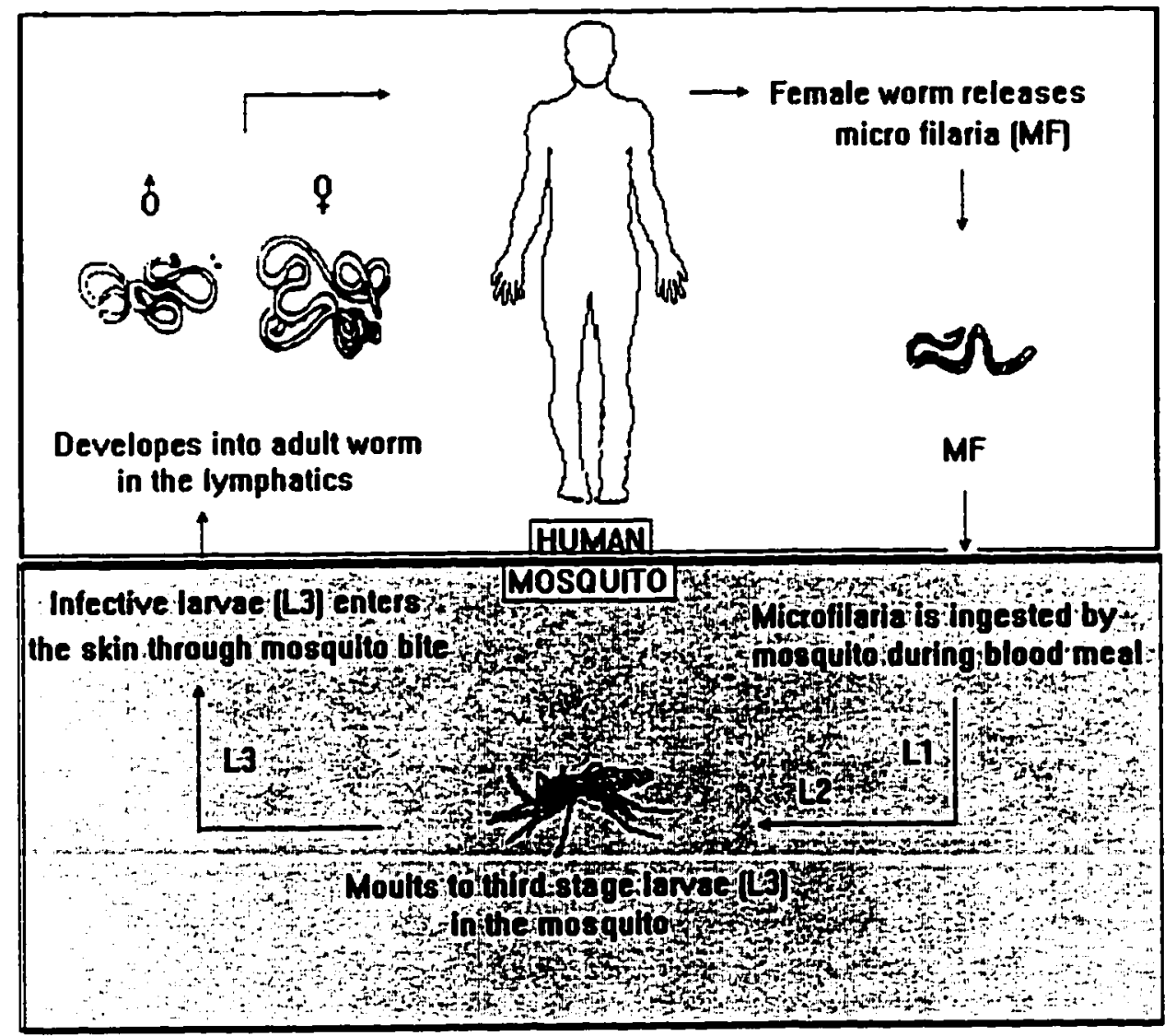

Diagrammatic representation of the life cycle of filarial parasites 


\section{CLINICAL GROUPS}

\section{Asymptomatic microfilaraemics (MF)}

Certain individuals in the population of an endemic area develop microfilaraemia but with no recognisable clinical manifestation of filariasis. In these individuals the presence of adult parasites in the lymphatics and of microfilariae in the blood stream can be tolerated for long periods without untoward effect. In vitro filarial antigen specific lymphocyte hyporesponsiveness (Ottesen et al., 1977) and the diminished production of IL-2 and IFN- $\gamma$ in response to parasite antigen (Nutman et al., 1987) are the hallmarks of MF individuals. However, the in vitro lymphocyte response of these individuals to nonparasitic antigens and mitogens is normal (Nutman et al., 1987).

\section{Asymptomatic amicrofilaraemics ('Endemic Normals', EN)}

In endemic areas a proportion of the population shows absolutely no clinical or parasitological evidence of infection. Their immune responsiveness to parasite antigens is significantly greater than that found in subjects with microfilariae (Ottesen et al., 1977).

\section{Symptomatic amicrofilaraemics ('Chronic pathology', CP)}

While some MFs remain asymptomatic for decades, a smaller number of people develop chronic lymphatic disease, oedema, fibrosis, and eventually the irreversible state of elephantiasis. Other clinical manifestations of chronic bancroftian filariasis include hydrocoele and chyluria. Patients with chronic pathology suffer a variety of lesions but 
carry few, if any, circulating parasites. These individuals with chronic disease and low parasite numbers have considerably more vigorous antigen specific $\mathrm{T}$ cell responses [Piessens et al., 1980 (a)] than do the MFs with high microfilarial loads and ENs.

\section{TREATMENT}

Despite encouraging progress towards identifying promising molecular targets for intervention with vaccines, chemotherapy remains the single most effective, efficient, and inexpensive method to control parasitic infections (Webster, 1992). Antihelminth agents act either locally to expel worms from the gastrointestinal tract or systemically to eradicate helminths that invade organs and tissues. Such drugs are extremely important because helminthiasis affects over 2 billion people in the world and the prevalence is rising. Simultaneous infection with more than one type of parasitic helminth is common in many tropical regions (Webster, 1992).

Helminths have a characteristic nervous system in that the nerve axons are unmyelinated and, thus, are more susceptible to disturbances of nerve membranes. There are cholinergic and gamma-aminobutyric acid (GABA)ergic synapses at the neuromuscular junctions, as well as in the central ventral cords of the worms (Wang, 1984). The mammalian host, on the other hand, has mainly nicotinic cholinergic receptors at the neuromuscular junctions, and the GABA nerves are all confined within the central nervous system protected by the blood-brain barrier (Wang, 1984). Piperazine derivatives used as antihelminth drugs act at the neuromuscular junction and cause flaccid paralysis of the nematodes (Wang, 1984). 


\section{Diethylcarbamazine (DEC)}

DEC was synthesized as a 1-diethylcarbamyl-4-methylpiperazine derivative (Hewitt et al., 1947) and is the best drug of choice available at present in treating human lymphatic filariasis caused by $W$. bancrofti and B. malayi (Duke, 1980). DEC is used in the form of the dihydrogen citrate under the names Hetrazan, Banocide, and Notezine (Ottesen, 1985). DEC causes the rapid clearance of microfilariae of $W$. bancrofii and $B$. malayi from the blood of humans. DEC decreases the muscular activity and eventually immobilizes the organism. This may result from a hyperpolarizing effect of the piperazine moiety, and it causes dislocation of the parasite from the normal habitats in the host (Langham and Kramer, 1980). The drug also produces alterations in the microfilarial surface membranes, thereby rendering them more susceptible to destruction by host defence mechanisms (Hawking, 1979; Mackenzie and Kron, 1985). There is presumptive evidence that DEC kills adult worms of $W$. bancrofti and $B$. malayi but the mechanism of adulticidal action is unknown (Hawking, 1979). Dreyer et al. (1995) have demonstrated by ultrasonography, the adulticidal activity of DEC. The drug may aiso effect specific immune and inflammatory responses in the host by as yet undefined mechanisms.

The toxicity of DEC is very low. Nonetheless, a temporary systemic response is observed in patients undergoing DEC treatment. It usually consists of fever, oedema. intense itching, swelling, tenderness of the lymph nodes and headache. Most of the toxic reactions which follow DEC treatment are related to the release of inflammatory 
mediators by host cells or manifestations resulting from the release of products liberated by decomposition of the dead or dying worms (Zheng et al., 1991). Some drug-related side effects are also common [Dreyer et al., 1994 (b)]. Although it has been reported by Ottesen (1985) that the adverse reactions following DEC treatment are directly proportional to the microfilarial density, Dreyer et al. [1994 (b)] have demonstrated that the systemic adverse reactions observed in their study did not appear to be related to the microfilaricidal density before treatment. However, once triggered, systemic adverse reactions were significantly more severe in carriers with high microfilarial counts [Dreyer et al., 1994 (b)]. DEC is considered to be effective against both microfilariae and the adult worms (Ottesen, 1985). However, its acceptability for community control programs is limited by the associated systemic and local adverse reactions, and by current recommendations that the drug be given for 12 consecutive days [World Health Organisation (WHO), 1992].

\section{DOSAGE}

The most generally accepted standard dosage of DEC for the treatment of bancroftian filariasis is $6 \mathrm{mg} / \mathrm{kg}$ of body weight orally for 12 consecutive days, given preferably in divided doses after meals (WHO, 1992). It is assumed that this recommended course of treatment will clear the microfilariae of most patients but complete parasite clearance will require repeated courses of treatment.

Ottesen (1994) has reported that a single dose of DEC (6 mg/kg) is essentially equivalent to a full 12 days of treatment with the drug. Further it has been shown by Mataika $e t$ al. 
(1993) that the single annual dose of DEC is equivalent in efficacy compared to multiple long-term standard DEC regimens.

According to the report of WHO (1994), recommendations have been made to change the older 'standard' 12 day course of DEC for the treatment of bancroftian filariasis. The use of DEC (Hawking, 1979; Mackenzie and Kron, 1985; and Ottesen, 1985) and Ivermectin (Jenkins, 1990) as antifilarial drugs have been very well reviewed and are recommended alone or in combination. The WHO report (1994) proposed that mass distribution programs must replace those based on a selective treatment in endemic areas. The recommended regimes for mass treatment would be one of the following:

- DEC-fortified salt $(0.2-0.4 \% \mathrm{w} / \mathrm{w})$ for a period of $9-12$ months.

- Single annual or semi-annual mass administration of DEC (6 mg/kg body weight).

- Ivermectin $(400 \mu \mathrm{g} / \mathrm{kg})$ once yearly.

- Ivermectin ( $400 \mu \mathrm{g} / \mathrm{kg}$ ) plus DEC (6 mg/kg) given once yearly.

\section{RECENT TECHNICAL ADVANCES IN THE STUDY OF FILARIASIS}

\section{Ultrasonography}

The use of ultrasonography has permitted direct localization and visualization of live adult filarial worms in their natural habitat in patients with human lymphatic filariasis. The parasites preferentially localize in the scrotal area of infected men (Amaral et al., 1994). Compared to conventional methods such as lymphangiography and more recently lymphoscintigraphy (which do not identify or directly visualize the adult parasites), this 
method is technically more feasible, non-invasive, rapid, cheap, and most useful in endemic areas where it can be used to detect adult worms in vivo. These adult worms exhibit a peculiar pattern of movement called the "filarial dance sign." They are clustered together at definite sites where they seemingly attach themselves to the lymphatic endothelium. A characteristic feature of ultrasonography is that it is useful to directly assess in vivo the effect of antifilarial drugs on the adult worms [Dreyer et al., 1994 (a)].

\section{Lymphoscintigraphy}

Lymphoscintigraphy, a recent non-invasive technique, is now used as the optimal procedure for visualizing lymphatic vessels and lymph nodes in individuals with lymphatic filarial infections. Radiolabelled colloid albumin or dextran injected intradermally or subcutaneously is imaged using a gamma camera. The images of the superficial lymphatic system are recorded 2 and $4 \mathrm{~h}$ after isotope administration when the colloid collects in the lymphatics and joins the lymph flow, thereby giving functional and anatomical information about the state of the lymphatics (Dissanayake et al., 1995). Information from such studies reveals profound lymphatic abnormalities in individuals who are clinically asymptomatic and manifest the filarial infection only by the presence of circulating microfilariae. Their lymphatics are markedly dilated, with many collateral channels. Clearance of microfilariae by DEC therapy does not seem to alter or reverse this lymphatic pathology observed in microfilaraemic subjects (Freedman et al., 1995). Patients with elephantiasis show lymph stasis and dermal back flow as well as abnormal 
vessels. Their lymphatic vessels are dilated and the abnormalities observed do not change with DEC treatment (Freedman et al., 1995).

\section{RECOMBINANT PARASITE ANTIGENS IN FILARIASIS}

Recombinant DNA technology can be used to identify filarial antigens from $W$. bancrofti genomic libraries which may further our understanding of the dynamics of the host parasite relationship and lead to production of large amounts of defined parasite antigen. In addition, screening of potential recombinant proteins for their role in eliciting immune responses will be useful in developing protective vaccines for filariasis.

Recently, considerable progress has been made in the use of recombinant parasite antigens for the serologic diagnosis of lymphatic filariasis (Dissanayake et al., 1994). T and $\mathrm{B}$ cell responses have been studied among different clinical groups using Brugia malayi adult worm antigen $(\mathrm{BmA})$ and a $58 \mathrm{kDa}$ recombinant $W$. bancrofti parasite protein antigen, pRJ5I (Regunathan, 1996). The lymphocyte proliferative responses to BmA and pRJ5! were similar in CPs and ENs. In MFs, the proliferative response to pRJ51 was significantly greater when compared to the response to $B m A(p<0.001)$. Further, pRJ51 reacted with sera from all clinical patient groups including ENs, but did not react with sera from individuals infected with other nematode infections (Regunathan. 1996). 


\section{EFFECT OF DEC TREATMENT ON THE HOST IMMUNE RESPONSE}

Epidemiological aspects and efficacy of DEC treatment have been studied. However, the molecular mechanisms of action of DEC in modulating the host immune system during the period of DEC treatment have not been characterized. We report here on the host cellular and humoral immune responses during 14 days subsequent to the recommended standard 12 day DEC treatment regime.

Since plasma from patients with $W$. bancrofti infections cross reacts with $B$. malayi, and since $W$. bancrofti antigens are not available, $\mathrm{BmA}$, a well characterized preparation (Ottesen et al., 1977) of adult male and female worms of $B$. malayi (maintained in jirds, a gift from Dr. Thomas Nutman, Laboratory of Parasitic Diseases, National Institute of Allergy and Infectious Diseases, National Institute of Health, MD $\{\mathrm{NIH}\})$ was used as a source of parasite antigen in the current study. The levels of filarial specific circulating antigens and circulating neutrophils and eosinophils are also reported. 


\section{LITERATURE REVIEW}

\section{HELMINTH INFECTIONS : BIOLOGICAL FEATURES}

The most striking features of multicellular parasitic helminths are long term persistence within the host and the complex developmental cycles involving stage-specific antigens. They pose unique problems to the host. Helminths cause morbidity rather than mortality, with disease severity typically related to worm burden (Maizels et al., 1993). The persistent nature of infection with progressive accumulation of parasites can induce chronic sequelae such as hepatosplenic disease induced by Schistosoma mansoni. lymphoedema and elephantiasis driven by $W$. bancrofti, B. malayi, and river blindness caused by Onchocerca volvulus (Maizels et al., 1993). Helminth parasitic infections are accompanied by immune responses that are similar and are characterized by IgE antibody production, eosinophilia, and the participation of inflammatory mediator cells such as basophils and mast cells.

\section{PARASITE DEFENCE STRATEGIES}

The helminth infections of greatest clinical importance in human and veterinary medicine often persist for many months and may be found in individuals of all ages. This common finding suggests that these parasites either fail to stimulate or have evolved methods of evading the host immune response. In contrast to protozoa, viruses, and bacteria that have direct reproduction within the host, helminths do not multiply within their definitive host. They reproduce sexually to produce transmission stages that are egressed via a 
biting arthropod vector (Maizels et al., 1993). Hence, an increase or decrease in worm population depends upon the intake of infective stages and the rate at which the mature stages disappear from the host. Thus, helminths induce long lasting chronic infections in which individual organisms persist over long periods of time in the host. At least three methods of immune evasion have been proposed to explain the longevity of helminth infections: (1) The parasites assume a disguise of molecules resembling that of the host which mask the crucial antigens and fail to stimulate an immune response; (2) the immune response is misdirected, i.e. the parasites stimulate an immune response, which. though capable of recognizing the worms, cannot affect them. This could happen if the immune response is directed against antigens which are unimportant for the survival of the worms or if the wrong kind of immune response is stimulated; and (3) the worms react to the immune response by altering the immunogenecity of their antigens. A key facet of parasite persistence appears to be down-regulation of the immune system resulting in tolerance or anergy.

Parasites can directly or indirectly block the effects of antibody with surface or released proteases capable of degrading host immunoglobulin molecules (Auriault et al., 1981). Filarial parasites use endogenous and exogenous arachidonic acid to produce and release prostanoids (prostracyclin and PGE2), which, in addition to anti-inflammatory properties, may also inhibit T-cell proliferation (Liu et al., 1990). Thus, helminth parasites successfully combine specific molecular strategies to combat the threat of immune attack by the host. 


\section{CIRCULATING ANTIGENS IN FILARIASIS}

Circulating filarial antigens were first demonstrated in bancroftian filariasis by Franks (1946) using the technique of passive cutaneous anaphylaxis. Weil et al., (1987) have compared monoclonal antibody (mAb) (AD12.1) based enzyme immunoassay in the diagnosis of active $W$. bancrofti infections with conventional microfilarial tests which lack sensitivity and are inconvenient due to nocturnal periodicity of microfilariae. They have demonstrated that ADi2.1 detects circulating antigens of molecular weight 200 $\mathrm{kDA}$ and does not exhibit cross reactivity with non endemic sera and sera from patients with filarial infections other than W. bancrofti. Further, More and Copeman (1990) developed a highly specific mAb $(\mathrm{Og} 4 \mathrm{C} 3)$ based sandwich ELISA for detecting circulating antigens in human sera. They have reported that the antigen detected by Og4C3 was highly specific for W. bancrofti infections and detects circulating excretorysecretory (ES) antigens from W. bancrofti adult worms of molecular weight $50-60 \mathrm{kDa}$ and $130 \mathrm{kDa}$. More and Copeman (1990) proposed two reasons to reason that antigens detected by $\operatorname{Og} 4 \mathrm{C} 3$ are not solely of microfilarial origin and circulate independently from microfilariae. They found that the microfilaria counts and circulating antigen levels in sera from patients with active $W$. bancrofti infections were weakly correlated, and that high levels of circulating parasite antigens were detected in CPs.

The levels of circulating antigens reflect the balance between antigen production by living adult worms and constant antigen clearance in the host (Weil et al., 1987). There is no direct evidence correlating the levels of circulating antigens and adult worm counts 
in W. bancrofit infections. However, circulating antigen levels have been shown to correlate significantly with adult worm counts in several animal models (Weil et al., 1985 and 1990). It is presumed that this relationship also applies to $W$. bancrofti infections in humans (Weil et al., 1996).

\section{CELLULAR IMMUNE RESPONSE IN FILARIASIS}

\section{Th1 and Th2 type cytokines}

Upon antigenic stimulation, CD4+ T helper (Th) cells differentiate into two distinct sub populations, the T - helper 1 (Th1) or T - helper 2 (Th2) cells, each producing unique cytokines and mediating separate effector functions (Mossmann and Coffman, 1989). Thl cells produce interleukin-2 (IL-2), tumour necrosis factor $\beta$ (TNF- $\beta$ ) and interferon- $\gamma$ (IFN- $\gamma$ ), thereby activating macrophages and inducing delayed type hypersensitivity (DTH) responses and cell mediated immunity. Th2 cells produce IL-4, IL-5, IL-10, and IL-13 stimulating production of mast cells, eosinophils, IgGI and IgE antibodies. Th2 cells are also involved in promoting humoral immunity, possibly suppressing the cellular immune response. Each subpopulation regulates the other via their different cytokine profiles.

\section{Interleukin 2 (IL-2)}

IL-2, formerly described as T cell growth factor, controls proliferation of $\mathrm{T}$ lymphocytes. IL-2 is produced exclusively by $\mathrm{T}$ lymphocytes in response to antigen or mitogen stimulation (Clemens, 1991). IL-2 is secreted mainly by Th cells 4-12 hr following 
stimulation by binding of antigen to the $T$ cell receptor. Binding of $I L-2$ to its receptor on Th cells enhances proliferation of these cells, secretion of lymphokines, expression of membrane receptors for other growth factors (e.g. transferrin receptor, insulin receptor), and expression of class II molecules of the major histocompatibility complex (MHC). The biological effects of IL-2, although originally defined on the basis of the growth of $T$ cells in culture, are now known to include interactions with macrophages, activated B cells, natural killer and other cytotoxic cells, leading to its use in immunotherapy for cancer and infectious diseases.

Complementary DNA (cDNA) for human IL-2 has been cloned from a number of human cell sources and the gene for IL-2 has been mapped to chromosome 4 (Clemens, 1991). It encodes a polypeptide chain of 133 amino acid residues plus a signal sequence of 20 residues (Clemens, 1991). The cDNA sequence is given in appendix I.

\section{Interleukin 10 (IL-10)}

IL-10 was initially described as cytokine synthesis inhibitory factor (CSIF), produced by mouse Th2 clones (Fiorentino et al., 1989). IL-10 is also a co-stimulatory molecule for proliferation and differentiation of B cells and can serve as a cofactor for stimulating growth and differentiation of $T$ celis, mouse thymocytes and mouse myeloid cells (Moore et al., 1993). The mouse IL-10 and human IL-10 cDNA clones share $80 \%$ homology in the DNA sequence (Moore et al., 1995). The gene for $\mathrm{LL}-10$ has been mapped to chromosome 1 in the human and mouse (Kim et al., 1992). Recombinant IL-10 (rIL-10) 
is an $18 \mathrm{kDa}$ polypeptide (Moore et al., 1995). The cDNA sequence is given in appendix

II.

IL-10 is known to mediate suppression of cellular responses. IL-10 inhibits antigen specific $\mathrm{T}$-cell responses by acting on the antigen presenting capacity of the macrophages [Malefyt et al., 1991 (a)]. IL-10 has other effects on macrophage function including the inhibition of release of certain cytokines and chemokines [Malefyt et al., 1991 (a)], blocking IFN- $\gamma$ activation (Bodgan et al., 1991), and inhibiting production of reactive oxygen intermediates (Gazzinetti et al., 1992).

\section{Parasites and Th1/Th2 cytokines}

The major immunologic hallmarks of helminth infection are eosinophilia, elevated plasma IgE levels, and in the case of certain parasites, mastocytosis. Importantly, each of these responses is stimulated by cytokines or cytokine combinations characteristic of Th2 cells (Modlin and Nutman, 1989); for example, IgE by IL-4, eosinophilia by IL-5 and mastocytosis by $\mathrm{IL}-3, \mathrm{IL}-4$ and $\mathrm{IL}-10$. Furthermore, both mouse and human $\mathrm{T}$ lymphocyte clones or populations with a characteristic Th2 cytokine production profile can be derived from parasitized hosts by stimulation with worm antigens or mitogen (Wilson, 1993). The differentiation of Th precursor (Thp) cells into Thl or Th2 cells has important biologic implications in terms of susceptibility or resistance to a particular disease. Infection with helminths leads to a dramatic induction of the Th2 lymphocyte subset, which is well characterized in rodent models by induction of $\mathrm{IL}-4$ and down- 
regulation of IFN- $\gamma$, resulting in the stimulation of $\operatorname{IgGl}$ isotype and IgE antibodies (Allen and Maizels, 1996). Despite the induction of Th2 responses to parasite antigens following helminth infection, it is uncertain whether this response is beneficial to the host or the parasite (Maizels et al., 1993; Wilson, 1993). However, in murine schistosomiasis, established infection is associated with strong Th2 responses while protective immunity induced by vaccination with irradiated cercariae correlates with elevated Thl cytokine production and is partially ablated by treatment of the vaccinated mice with mAbs against IL-2 receptor or IFN- $\gamma$ (Urban et al., 1991 and 1992).

\section{IMMUNOLOGICAL TOLERANCE : AN OVERVIEW}

In the human immune system, tolerance is effected by pre- and neo-natal elimination of most self reactive $\mathrm{T}$ cell clones in the thymus. A secondary level of tolerance may operate primarily by inactivation rather than deletion. Several mechanisms of postthymic or peripheral $\mathrm{T}$ cell tolerance have been investigated. Immunity versus tolerance in mature peripheral $\mathrm{T}$ cells is determined by the nature of antigen exposure. For example, an autoantigen injected in an emulsion with adjuvant induces autoimmunity. whereas the same antigen injected intravenously in a deaggregated form or fed orally makes the animal tolerant against future autoimmunity. Unresponsiveness has been induced in $\mathrm{T}$ cell clones by pretreating them with their cognate peptides in the absence of antigen presenting cells (APC) (Lamb et al., 1983). Clonal anergy is the functional inactivation of $\mathrm{T}$ cells after previous $\mathrm{T}$ cell stimulation, and may be due to antigen stimulation without appropriate costimulation (Lasalle and Hafler, 1994). 


\section{Immunological tolerance in Filariasis}

It has been recognized for years that MFs exhibit impaired $\mathrm{T}$ and $\mathrm{B}$ cell responses to filarial antigens [Ottesen et al., 1977; Piessens et al., 1980 (b)]. However, tolerance to filarial antigen does not shut down all immune responses. Lymphocyte proliferative responses to non-parasitic antigens such as Tuberculin Purified Protein Derivative and Streptococcal antigens are normal (Ottesen et al., 1977). Moreover, in MFs, filarial antigen specific IgG4 response is very strong and is generally accompanied by high levels of circulating microfilaria (Maizels et al., 1995). Interestingly, treatment of microfilaraemic patients with DEC restores the lymphocyte proliferative response to filarial antigen in vitro (Lammie et al., 1988; Steel et al., 1994).

\section{Mechanisms underlying antigen-specific immunosuppression in filariasis}

MFs are characterized by an inability of their lymphocytes to proliferate strongly in response to parasite-derived antigens or to produce gamma interferon (IFN- $\gamma$ ) and IL-2 to BmA (King and Nutman, 1991). The mechanisms underlying this antigen-specific hyporesponsiveness may involve adherent suppressor cells, serum suppressive factors or suppressor T lymphocytes [Piessens et al., 1980(b)]. Alternatively the anergic state may result from a diminished number of parasite antigen-responsive lymphocytes (Nutman et al., 1987) as a consequence of prenatal sensitization or tolerization to the parasite (Lammie et al.. 1988; Steel et al., 1994). Further, the frequency of parasite specific T cells and the proportion of lymphocytes producing parasite specific IgE or IgG may be 
diminished in some MFs (King et al., 1992), and in some instances, removal of downregulatory cytokines restores responsiveness (King et al., 1993). Recent studies have suggested that the antigen-specific Thl-type anergy seen in MFs is associated with high levels of spontaneous and parasite antigen-driven IL-10 secretion (Dimock et al., 1994; Mahanty et al., 1996). Further, it has been demonstrated by King et al., (1993) that parasite-specific Th2-type responses help regulate Thl subpopulations, as in vitro blockade of IL-10 and transforming growth factor $\beta$ from lymphocytes of MFs was partially able to restore proliferative responses to parasite antigens in a majority of MFs, but the basic process requires further study.

One of the possible reasons for hyporesponsiveness seen in MFs appears to be the antifilarial IgG4 antibodies which are made in relatively large amounts by the MFs. IgG4 has been implicated as the blocking antibody responsible for controlling IgE mediated allergic responsiveness to the parasite (Ottesen et al., 1981; Hussain and Ottesen, 1986; Maizels et al., 1991). IgG4 was first identified as a factor in the serum of MFs which inhibited antigen-mediated degranulation of basophils (Ottesen et al., 1981). In addition to host-produced products such as IgG4, molecules derived directly from the parasites inhibit human lymphocyte function in vitro (Bulletin of WHO, 1993). Since some of these same molecules have also been found circulating in the blood during active infection they might play a similar modulating role in vivo (Bulletin of WHO, 1993).

Th2 cytokines and relatively low lymphocyte proliferative responses to filarial antigens are found in MF individuals (King et al., 1993; Maizels et al., 1995; Mahanty et al., 
1996). This profile indicates low Thl activity and IL-2 production. IL-2 is the T cell growth factor which is largely responsible for $\mathrm{T}$ cell proliferation. Conversely, IL-10 production has been associated with the parasite antigen specific hyporesponsiveness in MF patients, and plays a role in downregulating antigen specific responsiveness in parasitic infections including filariasis (Urban et al., 1991 and 1992; Mahanty et al., 1996). Addition of neutralizing anti-IL-10 antibodies to antigen driven lymphocyte cultures enhanced $\mathrm{T}$ cell proliferation and subsequent Thl cytokine production (Pearlman et al., 1993). The mechanism of IL-10 suppression of lymphocyte proliferation may occur either through the ability of IL-10 to inhibit expression of MHC class II molecules on APCs [Malefyt $e^{r}$ al., 1991 (b)] or by inhibiting the expression of certain costimulatory molecules.

It has been demonstrated that $\mathrm{CPs}$ exhibited both Th2 and Th1 like $\mathrm{BmA}$ driven response (Ravichandran et al., in press, 1997). However, MFs show a marked down regulation of the Th1 type cytokines with a parallel increase in Th2 cytokines, especially IL-10. The ENs exhibited purely a Thl type cytokine profile. In addition, the authors demonstrated a significant negative correlation between IL-10 mRNA levels and antigen driven PBMC proliferation, suggesting a potential role of IL-10 in parasite specific anergy seen in MF individuals. Regunathan et al. (in press, 1997) reported that addition of EN sera to lymphocyte cell cultures of MF patients seemed to reverse the hyporesponsiveness. 


\section{HUMORAL IMMUNE RESPONSE IN FILARIASIS}

The most distinctive feature of humoral immune response in filarial infection is the elevated levels of antifilarial IgG4 antibodies in MFs compared to CPs and ENs. It is not known whether these IgG4 antibodies is of particular benefit to the host, as this subclass is neither cytophilic nor complement-fixing (Ottesen et al., 1981), but one possibility is that IgG4 antibodies prevent IgE mediated allergic reactions either by competing with cell bound IgE for specific allergens or by inhibiting the binding of $\operatorname{IgE}$ molecules to cell surface receptors on mast cells or basophils (Ottesen et al., 1985). Yazdanbakhsh et al. (1993) have compared T cell responsiveness and antibody isotype levels among the different clinical groups. They reported an inverse correlation between $\mathrm{T}$ cell responses and antifilarial IgG4 levels indicative of active infection regardless of clinical status.

In animal models appearance of serum antimicrofilarial IgM has been correlated with the clearance of microfilarial parasites from the circulation (Thompson et al., 1981). In rats, infections with $\mathrm{L} 3$ infective stage of $B$. pahangi result in specific IgG1, IgG2a and IgM antibody responses throughout infection (Lawrence and Denham, 1993).

The possible role of $\lg E$ in defence against parasites was first established by work on the cell mediated killing of schistosomes in vitro, as well as by epidemiological studies in areas of endemic schistosomiasis and other parasitic diseases (Sutton and Gould, 1993). IgE-secreting B cells are abundant in the skin, lungs and gut which are the main sites of parasitic invasion. IgE elicits a range of cellular responses to parasite antigens resulting in anatomical and physiological changes which exclude parasites from the body. These 
include inflammation, itching, coughing, lacrimation, bronchoconstriction, mucus secretion, vomiting, and diarthoea, all common symptoms of allergic disorders (Sutton and Gould, 1993). However, the functional role of $\operatorname{IgE}$ in defence against filarial parasites needs to be investigated further.

Pritchard (1993) has reported the findings of Jarrett and Bazin (1974) and Dessaiant et al. (1975) who demonstrated that helminth infections disproportionately elevate plasma levels of total non-parasite specific IgE in the host. While the production of parasite specific IgE has been linked with host protection in some helminth infections (Hagan et al., 1991), the presence of high levels of total non-parasite specific IgE in the plasma appears to be beneficial to the parasite, as these molecules may saturate the available high affinity receptors (FCERIs) on the mast cells of the skin and basophils, thus preventing specific mediator release (Pritchard, 1993). It has been reported that filarial antigen nonspecific IgE makes up a larger proportion of total IgE in human lymphatic filariasis (Watanabe et al., 1996). However, its biological significance in this disease process is not clear.

IgG4 and IgE are often directed at the same antigenic determinants and the ratio between these two isotypes is a major factor in determining whether antigen triggers an IgEmediated hypersensitivity response, or whether excess IgG4 can act as an anti-allergic blocking antibody by competing with IgE for antigen binding (Lundgren et al., 1989) or high IgG4 expression results from a regulatory constraint which minimizes IgE production (Maizels et al., 1991). MFs have much higher ratios of IgG4:IgE than found 
in CPs, suggesting that sufficient levels of IgG4 may be involved in protection in MFs and IgE may mediate some pathogenic effects in CPs (Kurniawan et al., 1993).

Earlier studies have attempted to investigate the levels of filarial specific antibodies generated before and after DEC treatment, especially among MF individuals. The levels of serum and cellular IL-5 (Limaye et al., 1993), IL-6, TNF- $\alpha$ (Turner et al., 1994), IFN$\gamma$ (Sartono et al., 1995) using Bioassays and ELISA have also been reported before and subsequent to DEC treatment. Lymphoproliferative studies have also been carried out in pre- and post-DEC treatment (Ottesen et al., 1977). However, in filariasis. there have been no reports about the $T$ cell and $B$ cell responses in the same individuals before and during the period of chemotherapy with DEC.

MF patients constitute an interesting clinical group because (depending on the density of microfilaria in their blood) they develop inflammatory side reactions upon administration of DEC. Studies of this group of patients will be very useful because early detection of circulating microfilaria followed by chemotherapy could greatly reduce the parasite burden in these individuals as well as help in control and transmission of the disease in the community.

It is clear from the above review that there is a parasite specific $T$ cell hyporesponsiveness in MFs and DEC treatment breaks down the clonal anergy seen in MF individuals. This hypothesis was tested in the current study in a group of MFs who received DEC treatment for a period of 12 days $(6 \mathrm{mg} / \mathrm{kg}$ body weight). Cytokine 
profiles and BmA-specific PBMC proliferation and isotype antibody levels were estimated before and during chemotherapy. The levels of filarial-specific circulating antigens were compared before and after DEC chemotherapy, and circulating neutrophil and eosinophil levels were monitored. 


\section{OBJECTIVES}

1. To describe filarial parasite specific circulating antigen levels and clearance of microfilariae following chemotherapy.

2. To study the cellular immune responses of MFs receiving DEC treatment by BmAspecific lymphocyte proliferative response before and during chemotherapy (1 day, 7 days and 14 days after start of treatment) using $\left[{ }^{3} \mathrm{H}\right]$ thymidine incorporation assay.

3. To compare the levels of unstimulated and BmA stimulated expression of $\mathbb{L}-2$ and IL-10 genes before and on day seven after start of chemotherapy using Reverse Transcriptase Polymerase Chain Reaction (RT-PCR).

4. To compare by ELISA the levels of BmA-specific antibodies (IgG1, IgG2, IgG3. IgG4, IgM and $\operatorname{IgE}$ ) in MFs before and at different intervals during DEC chemotherapy ( 1 day, 7 days and 14 days after start of treatment).

5. To compare the levels of circulating neutrophils and eosinophils in MFs receiving DEC treatment. 


\section{MATERIALS AND METHODS}

\section{STUDY POPULATION}

For preliminary proliferation studies, $10 \mathrm{MFs}, 5 \mathrm{ENs}$ and $10 \mathrm{CPs}$ were chosen from an area in Madras, South India where infection with $W$. bancrofti is endemic. CP patients manifested lymphatic obstruction of the extremities. Blood was collected between 8 p.m. and midnight to evaluate the presence of microfilariae.

For chemotherapy studies, the study population was selected from individuals residing in Madras, South India, an area endemic for bancroftian filariasis. Patients were recruited from the National Filarial Control Unit, Madras, South India, after obtaining informed consent. Five MFs were included in this study. All patients were clinically asymptomatic. Circulating microfilarial counts were quantitated by filtration of $\mathrm{I} \mathrm{ml}$ of heparinized venous blood collected between 10 p.m. and midnight through a $3 \mu \mathrm{M}$ polycarbonate filter (Nuclepore Co., Pleasanton, CA). The mean microfilarial counts were $25 \mathrm{mf} / \mathrm{ml}$ of blood.

\section{CHEMOTHERAPY STUDY TREATMENT PROTOCOL}

Each of the 5 MFs selected for chemotherapy studies received a daily dose of DEC ( 300 $\mathrm{mg}$ ) orally for 12 days, as recommended by the WHO (1992). Venous blood (15-20 ml) was collected in heparanized syringes from each of the patients before treatment and on days 1,7 and 14 after the start of chemotherapy. 


\section{TOTAL LEUKOCYTE COUNT AND DIFFERENTIAL COUNT}

Peripheral blood mononuclear cells (PBMCs) were separated from freshly collected blood using Ficoll diatrizoate gradient (Lymphoprep, Nycomed Pharma, AS, Oslo, Norway) and the plasma was stored at $-20^{\circ} \mathrm{C}$ for use in the ELISA. Total white blood cell (WBC) and complete differential counts were done on each blood collection.

Total WBC counts and differential counts were performed as described in by Simmons (1989). Briefly, a 1:20 dilution of freshly drawn heparinized venous blood was made in WBC dilution fluid (1.5\% glacial acetic acid and $1 \%$ solution of gentian violet in distilled $\mathrm{H}_{2} \mathrm{O}$ ) and the suspension was mixed well. The counting chamber was charged with the diluted blood and the total cells in each of the four large corners of the counting chamber were counted. The total WBC count $/ \mathrm{mm}^{3}$ was expressed as:

\section{Number of cells counted $(\mathrm{N}) \mathrm{X}$ dilution factor (20) X depth factor (10)} Number of squares counted (4)

The differential count was performed by Leishman's Staining of the peripheral blood smear. One hundred cells were counted and were categorized into various types. The differential count was expressed as a percentage. The absolute count was calculated as follows:

Total WBC count $X$ percentage differential 
The absolute count $/ \mathrm{mm}^{3}$ for each differential was calculated for each individual and the mean and the standard error of the mean were calculated to plot the graph in Figure 6.

\section{DETECTION OF CIRCULATING FILARIAL PARASITE SPECIFIC ANTIGENS}

The circulating filarial antigen test was performed by sandwich ELISA using a mAb (Og4C3) based commercially available kit as prescribed by the manufacturer (JCU Tropical Biotechnology Pty Ltd., James Cook University of North Queensland, Townsville, Queensland, Australia 4811) (JCU). Briefly, the U-bottom polystyrene microtitre ELISA plates were pre-coated with $\mathrm{Og} 4 \mathrm{C} 3 \mathrm{mAb}$ specific for an adult worm $W$. bancrofti antigen. Plasma samples were treated with solutions A and B provided by the manufacturer to facilitate release of the antigens from antigen-antibody complexes. Fifty $\mu l$ of the treated plasma sample was added to each well. The captured antigen was detected by rabbit anti-Onchocerca antibody (JCU) followed by goat anti-rabbit IgG (whole molecule) conjugated with horseradish peroxidase (HRPO) (JCU). The color was developed using 2,2'-Azino-bis (3-Ethylbenz-thiazoline-6-Sulfonic Acid) (ABTS) as the substrate (JCU). Absorbance of the wells was determined using dual wave lengths (405 and $490 \mathrm{~nm}$ ) on a Biotek EL3IIsx ELISA reader (BIO-TEK Instruments, Inc. Winooski, Vermont). The results are expressed in arbitrary antigen units (A.U) using Onchocerca gibsoni antigen as a standard (JCU). The term antigen unit (A.U) was introduced because the proportion of the $\mathrm{Og} 4 \mathrm{C} 3$ target antigen in the total soluble antigen from male $O$. gibsoni is unknown. A sample of $100 \mathrm{~A} . \mathrm{U}$ is defined as the amount of the target antigen of $\mathrm{Og} 4 \mathrm{C} 3$ found in $100 \mathrm{ng}$ of total soluble antigen protein from male $O$. gibsoni (More 
and Copeman, 1990). Values of the test results (in A.U) were calculated from the following formula [Personal communication, Dr. Thomas Nutman (NIH)]:

$\mathrm{Y}=(\mathrm{A}-\mathrm{D}) / 1+(\mathrm{X} / \mathrm{C})^{\mathrm{B}}+\mathrm{D}$ where $\mathrm{A}, \mathrm{B}, \mathrm{C}$, and $\mathrm{D}$ are constant values.

$(A=0.0157 ; B=2.51 ; C=340 ;$ and $D=0.878) ; Y=O D 405 / 490 \mathrm{~nm}$ and

$X=$ antigen units.

In order to test the validity of the formula, we substituted the OD 405 and $490 \mathrm{~nm}$ values obtained for the standards supplied with the kit (JCU) in the above formula for calculating the antigen units and found that the values were comparable with the antigen units provided by JCU.

\section{ANTIGEN AND MITOGEN FOR PRELIMINARY PROLIFERATION AND CHEMOTHERAPY STUDIES}

As there is no animal model for $W$. bancrofti filarial infections, and hence no ready source of antigens, BmA [a gift from Dr. Thomas Nutman (NIH)] was used as the parasite antigen in the current study. BmA obtained from NIH was prepared as described by Ottesen et al., 1977. Briefly, saline extracts of both male and female adult worms of B. malayi (maintained in jirds) were made by pulverization of previously frozen $\left(-20^{\circ} \mathrm{C}\right)$ worms in a micro-homogenizer. The pulverized material was extracted into saline at $37^{\circ} \mathrm{C}$ for $4 \mathrm{~h}$ and then overnight at $4^{\circ} \mathrm{C}$. Following centrifugation at $400 \mathrm{~g}$, the supernatant material was heated at $56^{\circ} \mathrm{C}$ for $1 \mathrm{~h}$. High-speed centrifugation at $20,000 \mathrm{~g}$ for $30 \mathrm{~min}$ yielded a soluble supernatant material which was passed through a $0.45 \mathrm{~mm}$ 
filter before storing in aliquots at $-10^{\circ} \mathrm{C}$. The complex antigenic preparation contains many antigens from male and female adult worms, microfilariae and infective larval stages. Phytohemagglutinin (PHA) (Burroughs Wellcome, Research Triangle, NC) was used as the mitogen control in preliminary proliferation studies.

\section{CHEMICALS}

Unless otherwise specified, chemicals were purchased from Sigma Chemical Company, (Sigma, St. Louis, MI) and were of analytical grade. RNA extraction was carried out using RNAZol (Tel Test, Friendswood, TX). Reverse transcriptase buffer, dithiothreitol (DTT), MMLV reverse transcriptase, RPMI medium, fetal calf serum and human $A B$ serum were obtained from GIBCO BRL, Gaithersburg, MD. Rnase Inhibitor (Rnasein) was purchased from Promega, Madison, WI. Primers and probes were synthesized at Micro Synth, Switzerland or received as gifts of Dr. Thomas Nutman, (NIH). Taq polymerase, deoxynucleotide triphosphates (dNTPs), Hybond- $\mathrm{N}^{+}$Nylon membrane and Enhanced Chemiluminescence (ECL) Kit (containing hybridization, detection and blocking reagents, and anti-flourescent antibody-HRPO conjugate) were purchased from Amersham International, Buckinghamshire, England, HP79LL, UK.

\section{CELL CULTURES FOR PBMC PROLIFERATION}

PBMCs were isolated from freshly collected heparinized venous blood by Ficoll diatrizoate gradient centrifugation by the method of Boyum (1968). Briefly, PBMCs (2 X $10^{5}$ cells/well) were cultured in triplicate in round bottom 96 well microtiter plates in 
$0.2 \mathrm{ml}$ of RPMI 1640 supplemented with gentamicin $(80 \mu \mathrm{g} / \mathrm{ml})$, HEPES (25 mM), and I $\mathrm{mM}$ glutamine (C-RPMI) with $10 \%$ human $\mathrm{AB}$ serum in the presence of $\mathrm{BmA}(5 \mu \mathrm{g} / \mathrm{ml})$, PHA $(10 \mu \mathrm{g} / \mathrm{ml})$ or medium alone in a humidified atmosphere with $5 \% \mathrm{CO}_{2}$ at $37^{\circ} \mathrm{C}$. After 5 days, $20 \mu$ l of plain RPMI medium containing $1 \mu \mathrm{Ci}\left[{ }^{3} \mathrm{H}\right]$-thymidine (Amersham. UK) was added to each well (including control wells) and cells were harvested $16 \mathrm{~h}$ later on a glass fiber sheet (Cambridge Technology, Inc., Cambridge, MA). $\left[{ }^{3} \mathrm{H}\right]$-thymidine incorporation was measured by liquid scintillation spectroscopy (LKB, Wallac, Finland). The stimulation index (S.I) was calculated by dividing the mean counts per minute (cpm) of antigen stimulated cultures by the mean cpm of unstimulated control cultures (medium alone).

\section{RNA EXTRACTION OF ISOLATED PBMCs}

PBMCs $\left(4 \times 10^{6}\right.$ cells $/ \mathrm{ml}$ ) were cultured in C-RPMI 1640 medium supplemented with $10 \%$ fetal calf serum in 24 well tissue culture plates for $18 \mathrm{~h}$ in the presence or absence of BmA $(5 \mu \mathrm{g} / \mathrm{ml})$. The RNA was extracted by the method of Chomczynski and Sacchi (1987). Briefly, PBMCs were collected from the 24-well tissue culture plate into an 1.5 $\mathrm{ml}$ microfuge tube and washed in RPMI medium. The supernatant fluid was discarded and $400 \mu$ I RNAZol was added to the pellet. The RNA was solubilized by disrupting the lysate several times with a pipette and adding $40 \mu \mathrm{l}$ chloroform, vortexing for 15 seconds and incubating on ice for $15 \mathrm{~min}$. Chloroform extraction was carried out by centrifuging at $12,000 \mathrm{rpm}$ for $15 \mathrm{~min}$ at $4^{\circ} \mathrm{C}$. The aqueous phase was aspirated and an equal volume of isopropanol was added. The RNA was precipitated by incubating at $-20^{\circ} \mathrm{C}$ for $2 \mathrm{~h}$ and 
centrifuging at $12,000 \mathrm{rpm}$ for $15 \mathrm{~min}$ at $4^{\circ} \mathrm{C}$. The RNA pellet was washed twice by centrifuging at $12,000 \mathrm{rpm}$ for $15 \mathrm{~min}$ at $4^{\circ} \mathrm{C}$ with $80 \%$ ethanol and dried in a speed vac (The Virtis Company, Gardiner, NY). The RNA was dissolved in $9 \mu$ l of Diethyl pyrocarbonate (DEPC) water.

\section{PRECAUTIONS UNDERTAKEN DURING RNA EXTRACTION}

All glassware was soaked and rinsed in a solution of $0.1 \%$ DEPC, autoclaved and baked at $180^{\circ} \mathrm{C}$ for $3 \mathrm{~h}$ before use. Gloves were used at all times when handling the samples to avoid degradation by RNAse from external sources.

\section{REVERSE TRANSCRIPTION OF RNA}

Total RNA was resuspended in $9 \mu$ DEPC-treated water and heated $\left(70^{\circ} \mathrm{C}\right.$ for $\left.5 \mathrm{~min}\right)$ after the addition of $100 \mathrm{pmol}$ of random hexamer (Boehringer Mannheim, Indianapolis, IN) in a total volume of $10 \mu \mathrm{l}$ and then chilled on ice. Reverse transcription of RNA was performed in a final volume of $20 \mu$ l containing $0.25 \mathrm{mM}$ mix of the four dNTPs (dTTP, dATP, dCTP, and dGTP), IX reverse transcriptase buffer ( $50 \mathrm{mM}$ Tris $\mathrm{HCl}, \mathrm{pH} 8.3,75$ $\mathrm{mM} \mathrm{KCl,} 3 \mathrm{mM} \mathrm{MgCl} 2), 8 \mathrm{mM} \mathrm{DTT}, 200 \mathrm{U} \mathrm{MMLV}$ reverse transcriptase; and $20 \mathrm{U}$ Rnasein. The reaction was carried out by incubating at $37^{\circ} \mathrm{C}$ for $60 \mathrm{~min}$ for polymerase addition of nucleotides. After heating to $90^{\circ} \mathrm{C}$ for $5 \mathrm{~min}$ (inactivating the polymerase), the reaction was cooled on ice for $3 \mathrm{~min}$. The final reaction volume was diluted 1:4 by addition of $60 \mu \mathrm{LEPC}$ water and stored at $-20^{\circ} \mathrm{C}$ until use. 


\section{PCR}

PCR standardization including selection of primers and internal probes and optimization of PCR conditions and cycle numbers was performed as described by Ravichandran (1996). PCR was performed under the following conditions: To $2 \mu \mathrm{l}$ cDNA. the following components were added: 1) $0.25 \mathrm{mM} \mathrm{dNTP}$ mix; 2) 1X PCR buffer (50 mM $\mathrm{KCl}, 10 \mathrm{mM}$ Tris $\mathrm{HCl}, \mathrm{pH} 8.3,1.5 \mathrm{mM} \mathrm{MgCl} 2)$; 3) $0.2 \mu \mathrm{M}$ sense and antisense primers; and 4) $0.15 \mathrm{U}$ Taq polymerase. PCR was performed by first incubating the reaction mixture at $95^{\circ} \mathrm{C}$ for $5 \mathrm{~min}$ (denaturation), followed by temperature cycling at $95^{\circ} \mathrm{C}$ for $\mathrm{l}$ $\min , 55^{\circ} \mathrm{C}$ for $1 \mathrm{~min}$, and $72^{\circ} \mathrm{C}$ for $1 \mathrm{~min}$. The total number of cycles was 36 for IL-2 and IL-10 genes and 40 cycles for the house keeping gene, hypoxanthine phosphoribosyl transferase (HPRT). Both positive and negative controls for the respective genes were included in each assay to confirm that no contamination of the cDNA had occurred. Positive controls contained known cDNA template for the respective genes prepared from mitogen induced cells in addition to other components mentioned above. Negative controls contained all components mentioned above except the cDNA template. In order to confirm an uniform amplification process, the HPRT gene was also amplified. The primers for the cytokines were as follows:

IL-2: 5'-ATG TAC AGG ATG CAA CTC CTG TCT T-3' and 5'-GTC AGT GTT GAG ATG ATG CTT TGA C-3';

IL-10: 5'- ATG CAC AGC TCA GCA CTG CT-3' and 5'-TCA GTT TCG TAT CTT CAT TGT CA-3'; 
HPRT: 5'-CGA GAT GTG ATG AAG GAG ATG G-3' and

5'-GGA TTA TAC TGC CTG ACC AAG G-3'.

\section{DETECTION OF PCR PRODUCTS BY NON-RADIOACTIVE SOUTHERN HYBRIDIZATION}

\section{Southern blotting followed by probe labeling}

For detection of PCR products, $20 \mu \mathrm{l}$ of the amplified DNA was electrophoresed in a $1.2 \%$ agarose gel that was then denatured $(1.5 \mathrm{M} \mathrm{NaCl}, 0.5 \mathrm{~N} \mathrm{NaOH})$, neutralized $(1.5 \mathrm{M}$ $\mathrm{NaCl}, 2 \mathrm{M}$ Tris- $\mathrm{HCl}, \mathrm{pH} 7.5$ ), and transferred by capillary action to nylon membranes as described by Maniatis et al., (1989). After baking at $80^{\circ} \mathrm{C}$ for $1 \mathrm{hr}$, the membranes were pre-hybridized at $42^{\circ} \mathrm{C}$ for $30 \mathrm{~min}$ in pre-hybridization buffer (ECL Kit) and hybridized overnight with cytokine specific internal probes that had been end labeled with fluorescein using terminal transferase enzyme (ECL Kit) according to the manufacturer's instructions. Briefly, the labeling reaction components were added to a $1.5 \mathrm{ml}$ microfuge tube in the following order: Oligonucleotide $\left(100 \times 10^{-12}\right.$ moles $)(2 \mu \mathrm{l})$, Fluorescein 11-UTP $(10 \mu \mathrm{l})$, Cacodylate buffer $(16 \mu \mathrm{l})$, distilled $\mathrm{H}_{2} \mathrm{O}(116 \mu \mathrm{l})$, and terminal transferase $(16 \mu \mathrm{l})$. The contents were mixed well and incubated at $37^{\circ} \mathrm{C}$ for $90 \mathrm{~min}$. The labeled probes were stored at $-20^{\circ} \mathrm{C}$ until use. The sequence of the probes used were as follows:

IL-2 5'-- GCC ACA GAA CTG AAA CAT CTT-3';

IL-10 5'-GCC ATG AGT GAG TTT GAC ATC-3';

HPRT 5'-GCT GAC CTGGAT TAC AT-3'. 


\section{Pre-hybridization}

The Nylon membranes were placed in a sealable bag containing hybridization buffer [ $5 \mathrm{X}$ sodium citrate sodium chloride buffer (SSC) $\mathrm{pH} \mathrm{7.0,0.1 \%} \mathrm{w/v} \mathrm{hybridization} \mathrm{buffer}$ component (ECL Kit), $0.2 \%$ w/v SDS, $5 \%$ w/v blocking agent (ECL Kit)] and prehybridized at $42^{\circ} \mathrm{C}$ for $30 \mathrm{~min}$ in a shaking water bath. The volume of buffer used for the hybridization was equivalent to $0.25 \mathrm{ml} / \mathrm{cm}^{2}$ of membrane. Fluorescein-labeled cytokine specific probes were added at a concentration of $5-10 \mathrm{ng} / \mathrm{ml}$ into the hybridization buffer and the membranes were further incubated at $42^{\circ} \mathrm{C}$ overnight in a shaking water bath.

\section{Stringency wash}

The blots were removed and placed in a clean glass tray and washed twice with an excess of $5 \mathrm{XSC}$ containing $0.1 \%$ SDS (in a rocker with agitation at room temperature) for 5 min. Blots were then washed twice in 1 X SSC containing $0.1 \%$ SDS for $15 \mathrm{~min}$ in a shaking water bath at $45^{\circ} \mathrm{C}$ for $15 \mathrm{~min}$.

\section{Membrane blocking and anti-fluorescein antibody probing}

The blots were washed in buffer $1(0.15 \mathrm{M} \mathrm{NaCl}, 0.1 \mathrm{M}$ Tris base $\mathrm{pH} 7.5)$ for one $\min$ and were placed in buffer 1 containing blocking solution (ECL Kit) and incubated for 30 $\min$ at room temperature with constant shaking. The blots were washed in buffer 1 for one $\min$. 
The blots were incubated for $30 \mathrm{~min}$ (at room temperature with constant shaking) with antifluorescein - HRPO conjugate (ECL Kit) diluted (1:1000) in buffer $2(0.4 \mathrm{M} \mathrm{NaCl}$, $0.1 \mathrm{M}$ Tris base $\mathrm{pH} 7.5$ ) containing $0.5 \%$ bovine serum albumin (BSA) (Sigma). The blots were washed three times with excess of buffer 2 for 5 min each, with agitation .

\section{Signal generation and detection}

Excess buffer 2 from the washed blots was drained and the blots were placed in a clean container. Detection solutions $\mathrm{I}$ and 2 (ECL $\mathrm{Kit}$ ) were mixed in equal volumes and were directly added to the blots and incubated for $1 \mathrm{~min}$ at room temperature.

Excess detection buffer was drained and the blots were placed between two transparencies or between seran wrap. The blots were placed in the autoradiography cassette (Hypercassette-ECL, Amersham, UK) by keeping the DNA side up. An autoradiography film (Hyperfilm-ECL, Amersham, UK) was placed on top of the blots and the cassette was closed. After 10-30 min exposure, the fluorography was developed using conventional photography developer and fixer.

To quantitate relative signals from PCR products for each cytokine, densitometric analysis of the resulting bands was performed (Molecular Dynamics, Sunnyvale, CA). The resulting individual OD values for each cytokine has been normalized with the respective HPRT OD values (Cytokine OD/HPRT OD*100). The mean of the normalized OD values was used for plotting the graph in figure 4. 


\section{ANTIFILARIAL ANTIBODY ELISA}

\section{ELISA for BmA-specific IgG isotypes and IgM antibodies}

The ELISA was performed by the method of Lal and Ottesen (1988). Briefly, flat bottom microtitre plates (Immulon 4, Dynatech Laboratories, Inc., Alexandria, VA) were coated with $100 \mu \mathrm{l}(10 \mu \mathrm{g} / \mathrm{ml})$ of $\mathrm{BmA}$ in carbonate buffer $\mathrm{pH} 9.6$ and incubated

overnight at $4^{\circ} \mathrm{C}$. The plates were washed in phosphate buffered saline (PBS) containing $0.05 \%$ Tween 20 (Sigma) (PBST) and the unbound sites were blocked with blocking buffer (PBS and 5\% BSA) for $2 \mathrm{~h}$ at $37^{\circ} \mathrm{C}$. After six washes with PBST, $100 \mu \mathrm{l}$ of plasma (collected from MFs before and during DEC treatment) was added in duplicate and incubated overnight at $4^{\circ} \mathrm{C}$. The plates were washed as above and $100 \mu \mathrm{l}$ of the recommended dilutions of anti-human IgG subclass specific and anti-human IgM ( $\mu$ chain specific) mouse monoclonal antibodies (IgG1, 1:2000; IgG2, 1:1000; IgG3, 1:1000; IgG4, 1:1000 and IgM, 1:5000) (Sigma) were added to the plates and incubated at $37^{\circ} \mathrm{C}$ for $2 \mathrm{~h}$. The plates were washed as above and further incubated at $37^{\circ} \mathrm{C}$ for $2 \mathrm{~h}$ with 1:500 dilution of alkaline phosphatase (ALP) conjugated goat anti-mouse IgG (whole molecule) antibody (Sigma). After six washes with PBST, the plates were developed using $p$-Nitrophenyl phosphate (pNPP) (Sigma) as substrate at a concentration of $1 \mathrm{mg} / \mathrm{ml}$ in substrate buffer (0.01 $\mathrm{M} \mathrm{NaHCO}_{3}, 0.01 \mathrm{M} \mathrm{Na}_{2} \mathrm{CO}_{3}, 0.001 \mathrm{M} \mathrm{MgCl}_{2} .6 \mathrm{H}_{2} \mathrm{O}, \mathrm{pH}$ 8.6). The reaction was stopped using $3 \mathrm{~N} \mathrm{NaOH}$. The absorbance at $405 \mathrm{~nm}$ was measured using a micro-plate ELISA reader (BIO-TEK Instruments, Inc. Winooski, Vermont). 


\section{ELISA for BmA-specific IgE antibodies}

The ELISA was performed according to the method of Lal and Ottesen. (1988). Briefly, flat bottom Immulon 4 microtitre plates (as above) were coated with $100 \mu \mathrm{l}(10 \mu \mathrm{g} / \mathrm{ml})$ of $\mathrm{BmA}$ in carbonate buffer $\mathrm{pH} 9.6$ and incubated overnight at $4^{\circ} \mathrm{C}$. The plates were washed in PBST and the unbound sites were blocked with blocking buffer as above for 2 h at $37^{\circ} \mathrm{C}$. After six washes, protein G (GammaBind G Sepharose, Pharmacia, Uppsala. Sweden) absorbed plasma samples (100 $\mu \mathrm{l})$ from MF patients (collected before and during DEC treatment) was added in duplicate and incubated overnight at $4^{\circ} \mathrm{C}$. Plasma samples were absorbed by incubating $25 \mu$ l of protein $G$ beads with $50 \mu l$ of plasma and $125 \mu \mathrm{l}$ of ELISA diluent (0.1\% BSA and $0.05 \%$ Tween 20 in PBS) overnight in a rocker at $4^{\circ} \mathrm{C}$. The wells were washed as before and incubated at $37^{\circ} \mathrm{C}$ for $2 \mathrm{~h}$ with $1: 2000$ dilution of anti-human IgE ( $\varepsilon$-chain specific) mouse monoclonal antibody (Sigma). The wells were washed as above and biotinylated goat anti-mouse IgG (Fab specific) (Sigma) was added at a dilution of $1: 3000$ and incubated at $37^{\circ} \mathrm{C}$ for $2 \mathrm{~h}$. After washing the wells as before, extravidin conjugated with ALP (Sigma) was added at a dilution of 1:7000 and the plates were further incubated at $37^{\circ} \mathrm{C}$ for one hour. After six washes, the plates were developed using pNPP as above. The reaction was stopped using $3 \mathrm{~N} \mathrm{NaOH}$ and the absorbance at $405 \mathrm{~nm}$ was measured as above. 


\section{STATISTICAL ANALYSIS}

Data are expressed as mean \pm SEM unless otherwise stated. The resuits of the $T$ cell proliferation assay among the CPs, MFs, and ENs were analyzed by the nonparametric Mann-Whitney test. Paired Student's t-test was performed to compare the experimental conditions before and during DEC chemotherapy. A value of $p<0.05$ was considered statistically significant for all the experiments. 


\section{RESULTS}

\section{PBMC proliferation}

There were differences in PBMC proliferative responses to BmA among the different clinical groups. MFs exhibited a significantly low proliferative response to $\mathrm{BmA}$ compared to CPs and ENs ( $p<0.001$ ). However, the PBMC proliferative response of the MFs to PHA was normal and was not significantly different from the responses seen in CPs and ENs (p>0.05) (Fig 1).

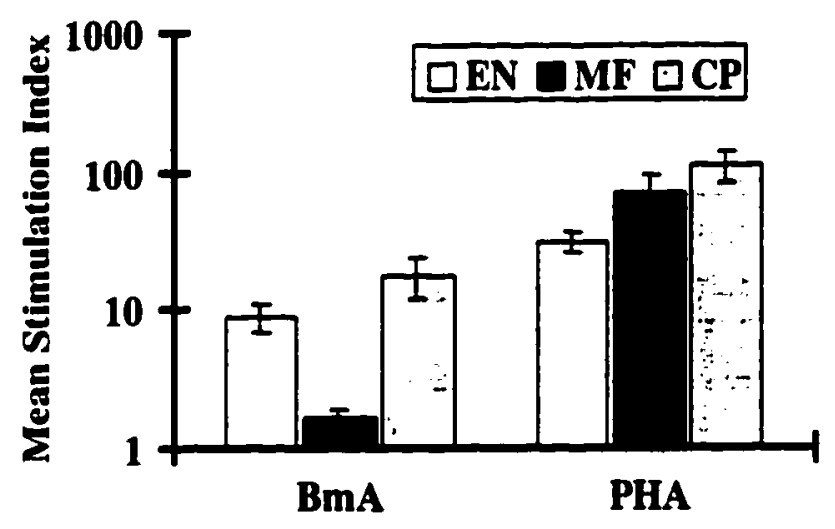

Figure 1: PBMC proliferative responses of ENs ( $n=5)$, MFs ( $n=10)$ and CPs $(n=10)$ to BmA and PHA. The mean stimulation index \pm SEM of each group is plotted in logarithmic scale.

Assessment of microfilarial density and filarial specific circulating antigen levels

DEC rapidly cleared the microfilaria from peripheral blood in MFs. This was evident from the zero levels of circulating microfilaria in the blood seen from the first day of DEC chemotherapy (Fig 2a). However, the levels of circulating antigens which were 
independent of microfilarial density remained stable after an insignificant reduction ( $p>0.05$ ) seen on the first day of DEC chemotherapy (Fig 2b).

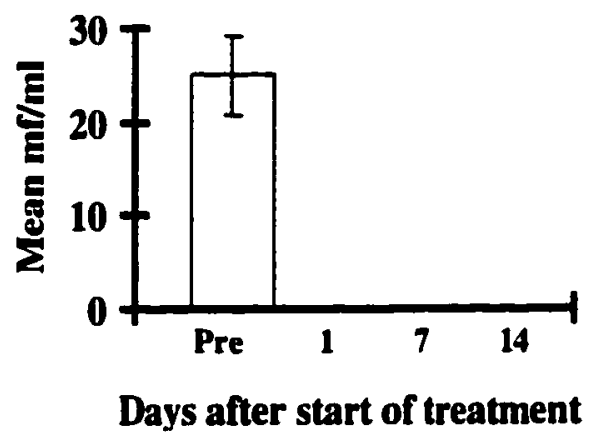

Fig 2(a): Mean \pm SEM values of microfilarial counts/ml of blood $(n=5)$ in MFs. Note zero levels of microfilariae by day one of DEC chemotherapy.

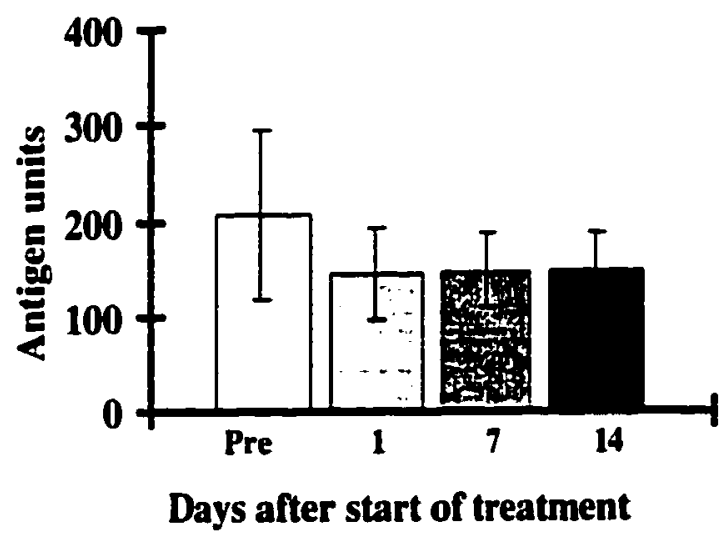

Figure 2(b): Filarial parasite specific circulating ES - adult worm antigen levels detected using a mAB (OgAC3) based sandwich ELISA. Antigen levels are expressed as arbitrary antigen units (A.U). Values are expressed as Mean \pm SEM values from 5 MF patients. 


\section{Effect of DEC treatment on BmA-specific PBMC proliferation in MF patients}

The PBMC proliferative response to BmA in MFs increased significantly $(p<0.05)$ on the first day of chemotherapy with DEC and decreased over 14 days to pre-treatment levels (Fig 3). On day 7 of treatment, the proliferative response was higher than pre-treatment levels, but the increase was not statistically significant $(p<0.1)$.

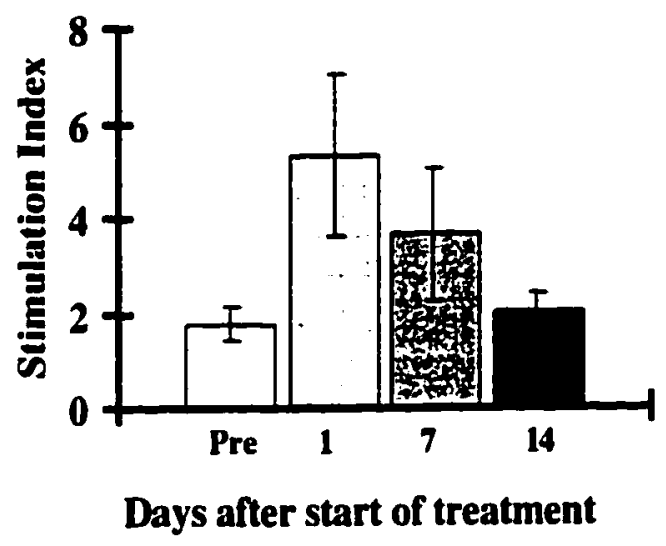

Figure 3: Effect of DEC chemotherapy on in vitro PBMC proliferative response to BmA in MFs $(n=5)$. Stimulation index (S.I.) is plotted against time after start of DEC $(6 \mathrm{mg} / \mathrm{kg} /$ day for 12 days) treatment. Values are expressed as Mean \pm SEM of S.I.

\section{Effect of DEC treatment on the levels of IL-2 and IL-10 on PBMCs from MFs}

PBMCs from three MFs were evaluated for unstimulated as well as BmA driven expression of the cytokine genes IL-2 and IL-10 before and on day 7 during DEC treatment. Among the unstumulated samples, there was a significant increase in the expression of IL-2 mRNA on day 7 ( $p<0.05)$, but there was no statistically significant ( $p>0.05$ ) increase in $\mathbb{L}-2$ levels in BmA stimulated PBMC cultures on day 7 of DEC treatment. The PBMCs of one of the patients did not show any expression of BmA 
stimulated IL-2 on day seven of DEC treatment, although there was an expression of IL-2 in the unstimulated condition (Fig 4a). The reason for the absence of IL-2 expression in the BmA stimulated PBMCs of this patient could be a technical error in the experiment because the expression of HPRT and IL-10 genes by the PBMCs of this patient was normal (Fig 4a). On the other hand, the increase in the levels of $\mathrm{IL}-10$ seen on day 7 of DEC treatment in the unstimulated PBMC cultures was not statistically significant ( $>0.05$ ). However, the IL-10 levels of BmA stimulated PBMCs showed significant increase on day 7 ( $p<0.05$ ) compared to pre-treatment levels.(Figs 4 a and $b$ ).

MEDIUM CONTROL IUNSTIMULATEDI

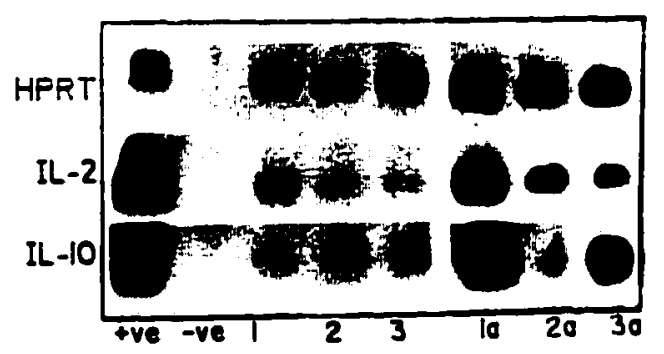

BmA STMULATEO

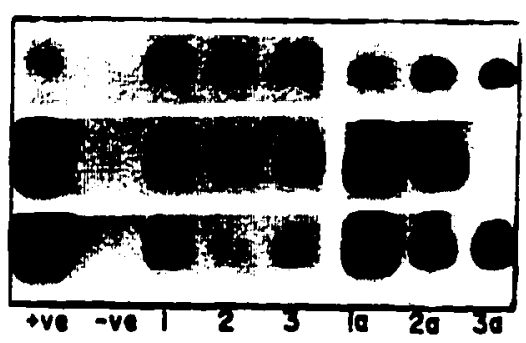

Figure 4(a) : Expression of HPRT, IL-2, and IL-10 genes in unstimulated (control cells in medium alone) and BmA stimulated PBMC cultures from 3 MF patient blood samples taken before and on day seven during DEC treatment. mRNA expression was measured by semi-quantitative RT.PCR followed by Southern hybridization. 1, 2, and 3 indicate pre-treatment levels of 3 MFs. 1a, 2a, and $3 a$ indicate seventh day levels of the same patients. 


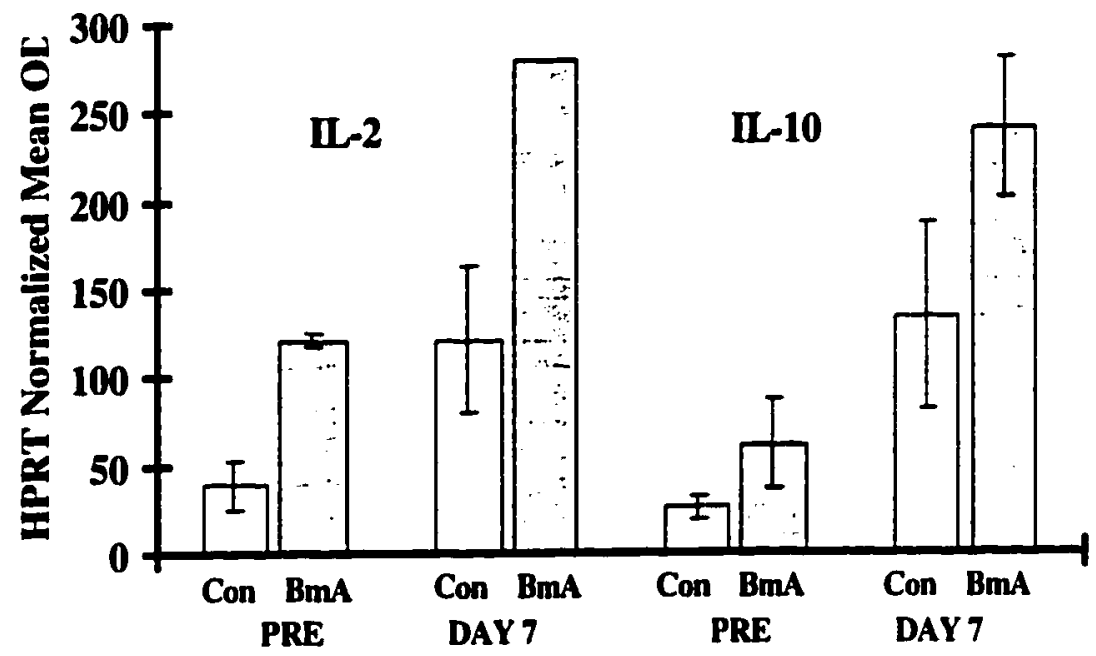

Fig 4 (b) : HPRT normalized mean ( $n=3$, except for $\mathbf{L L - 2}$ day seven BmA stimulated PBMC cultures, where $n=2)$ OD values of IL-2 and IL-10 genes obtained by densitometric analysis of figure in $4(a)$. Values are expressed as Mean \pm SEM (except for BmA stimulated IL-2 levels on day 7 of DEC treatment, n=2). Con - Unstimulated Control; BmA - BmA stimulated.

Effect of DEC treatment on the levels of BmA-specific isotype antibodies

Increases in the mean OD values of BmA-specific isotype levels of $\operatorname{IgG} 1, \operatorname{lgG} 2$, and IgG4 were observed by the end of the treatment period, but they were not statistically significant ( $p>0.05$ ). There were no differences in the levels of IgG3 (Fig 5a).

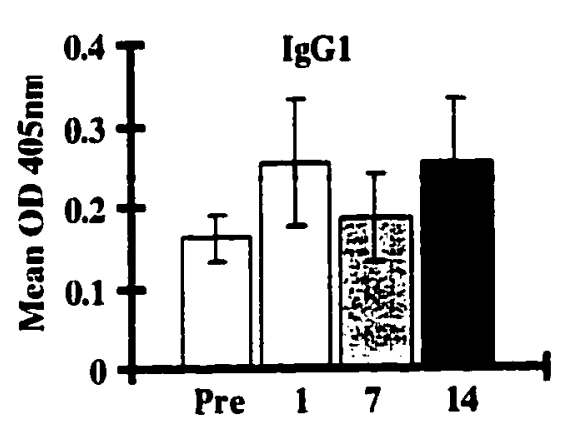

Days after start of treatment

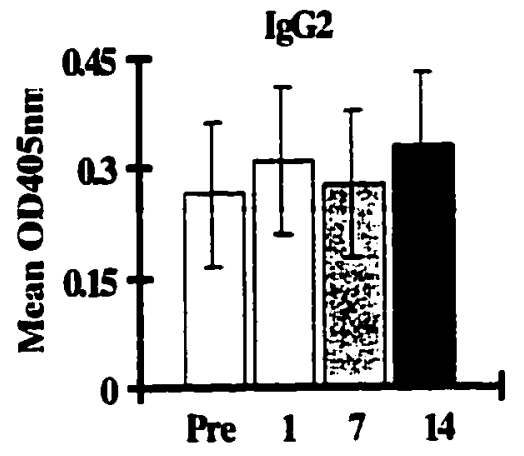

Days after start of treatment 


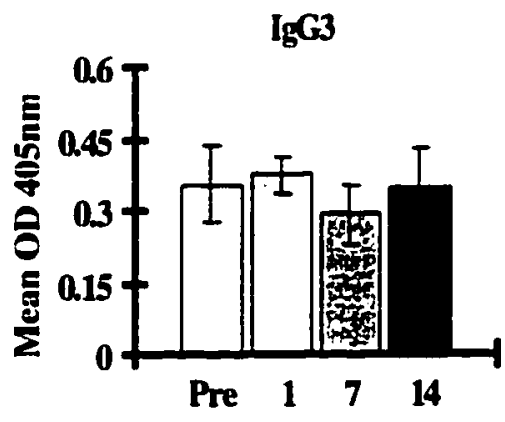

Days after start of treatment

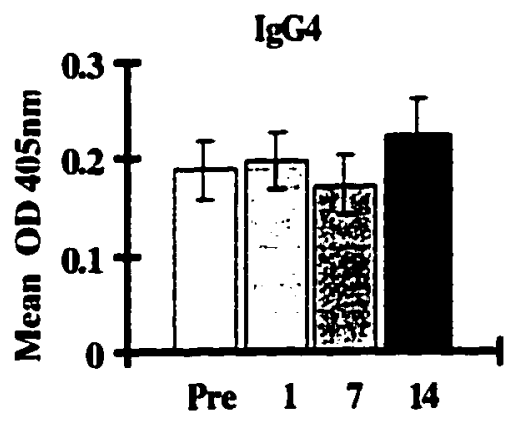

Days after start of treatment

Figure 5(a): Mean \pm SEM (n=5) OD(405 nm) values of BmA-specific isotype antibodies determined by isotype specific ELISA.

There were no differences in the levels of BmA-specific IgM and IgE before and after chemotherapy with DEC (Fig 5b).
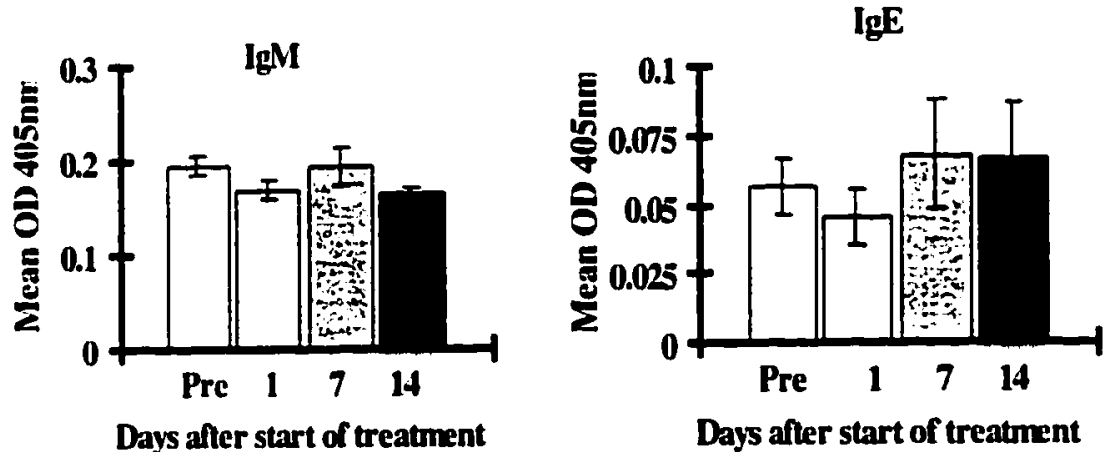

Figure 5(b): Mean \pm SEM ( $n=5)$ OD(405 nm) values of BmA-specific IgM and IgE determined by ELISA. 
Effect of DEC treatment on differential populations of peripheral blood leukocytes in MF patients

The levels of neutrophils were significantly higher on the first day $(p<0.01)$ and seventh day $(p<0.05)$ during treatment. By day 14 , their numbers had decreased to the control levels. Further it was observed that eosinophil counts were maximum on day 7 (significantly greater than pre-treatment levels, $\mathrm{p}<0.05$ ) and declined by day 14 after start of DEC treatment. When the levels of neutrophils and eosinophils increased, there was a corresponding decrease in the levels of the lymphocytes (Fig 6). There were no differences in the levels of circulating monocytes and basophils (data not shown).

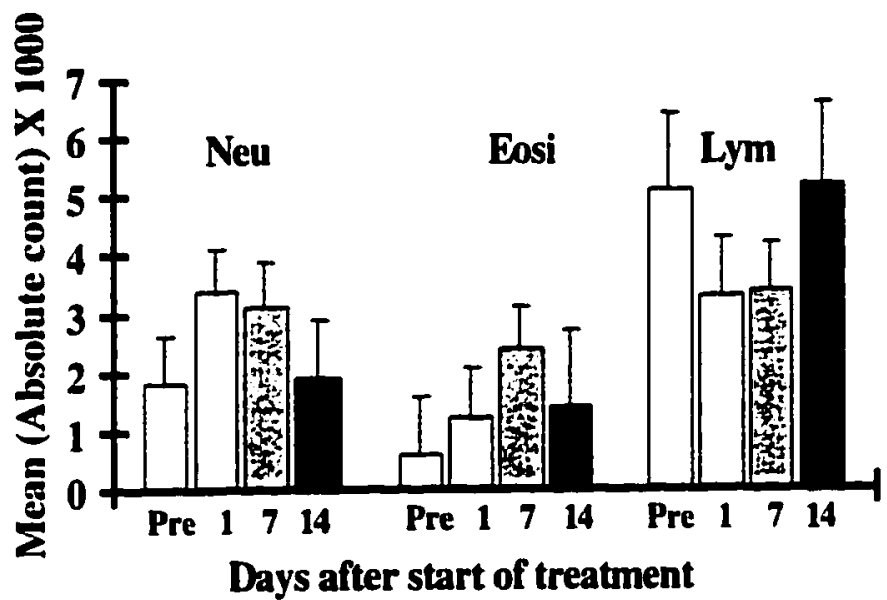

Figure 6: Mean absolute count + SEM ( $n=5$ ) of Neutrophils (Neu), Eosinophils (Eosi), and Lymphocytes $(\mathrm{Lym})$ per $\mathrm{mm}^{3}$ periphcral blood before and during DEC treatment. 


\section{DISCUSSION}

The human lymphatic filarial nematodes namely W. bancrofti, B. malayi and B. timori produce chronic infections which induce a broad spectrum of clinical manifestations. This spectrum ranges from immunologically responsive individuals with neither parasitological nor clinical signs of infection (ENs) to hyperresponsive patients (CPs) with clinical manifestations of tropical pulmonary eosinophilia (TPE) or chronic obstructive lymphatic disease. Chronic manifestations appear in the form of lymphoedema, hydrocoele, chyluria, and / or elephantiasis. Between the above two extremes, there are a large number of individuals in whom these infections are endemic (MFs). They are hyporesponsive and have microfilaria and circulating antigens in their blood but lack clinical symptoms.

Chemotherapy using DEC is shown to break down the immunological anergy that is seen in MFs (Maizels et al., 1995). This group of individuals deserve special focus as they act as carriers of the infective stage of microfilaria. Measures to control and eventually prevent the spread of human lymphatic filariasis have to be initiated in this group who serve as a reservoir of infection. The use of DEC [Hawking (1979), Mackenzie and Kron (1985). Ottesen (1985)] and Ivermectin (Jenkins, 1990) as antifilarial drugs has been very well reviewed. DEC is an excellent microfilaricide with macrofilaricidal properties (Ottesen, 1985). Ivermectin is extensively used as a microfilaricide against $O$. volvulus (Greene et al., 1985) and in trials against W. bancrofti infections (Diallo et al., 1986). The major shortcoming in the use of Ivermectin in the treatment of human lymphatic 
'filariasis is that it is not macrofilaricidal (Jenkins, 1990). Therefore, DEC remains the only drug of choice that is currently available for the treatment of human lymphatic filariasis. Although DEC is cheap, safe, and effective, mild to adverse reactions do occur in MFs as a result of chemotherapy with DEC and in some individuals, the side effects are directly proportional to microfilarial density (Ottesen, 1985). The mechanism of action of DEC and the association of DEC with the host immune response is poorly understood. In this study we investigated the cellular and the humoral responses before, during ( 1 day, 7 day), and on day 14 after start of DEC treatment. Further, the levels of filarial parasite specific circulating antigens were assessed before and during chemotherapy in order to evaluate the use of circulating antigen levels as a marker for clearance of microfilariae following chemotherapy with DEC. The levels of circulating neutrophils and eosinophils were also monitored.

MFs exhibit a depressed $T$ cell proliferative response specific to $B m A$ in vitro when compared to the responsiveness seen among CPs and ENs. (Fig 1). The lack of $T$ cell proliferative response presumably reflects ongoing active infection in these individuals. which suppresses specific T cells. Leiva and Lammie (1989) have reported that in animal models of filarial infections, induction of unresponsiveness coincided with the appearance of microfilariae in the blood stream. This suggested that a product of the microfilarial stage might be involved in immunomodulation. Sartono et al. (1995) have also demonstrated that the anergy seen in MFs reversed after one year as a result of chemotherapy with DEC. 
In the current study circulating filarial antigens were quantitated by mAb $(\mathrm{Og} 4 \mathrm{C} 3)$ based sandwich ELISA before and during DEC treatment. From the results it is seen that DEC cleared the microfilariae by day one of chemotherapy (Fig 2a). All the MFs were positive for filarial specific circulating antigen levels before and during DEC treatment (Fig 2b) and the levels of circulating antigens were insignificantly reduced by day one $(p>0.05)$. The stability of the circulating antigens seen after chemotherapy has also been observed by Chanteau et al. (1994) who reported the use of $\mathrm{Og} 4 \mathrm{C} 3$ based assay for the detection of active $W$. bancrofti infections. The authors have suggested that the antigen detected by $\mathrm{Og} 4 \mathrm{C} 3 \mathrm{mAb}$ is neither constitutively secreted by the microfilariae nor is a major ES microfilarial antigen and have demonstrated by indirect methods that the antigen detected by $\mathrm{Og} 4 \mathrm{C} 3$ is excreted mainly by adult worms. Further, Chanteau et al. (1994) have reported that the levels of circulating antigens detected by $\mathrm{Og} 4 \mathrm{C} 3 \mathrm{mAb}$ in MFs and CPs is a better marker of active infection and an indicator of adult worm burden. Complete clearance of circulating antigens by 18 months after chemotherapy with DEC has also been documented by McCarthy et al. (1995).

More recently, Dimock et al. (1996) compared circulating antigen levels detected using Og4C3 based assay with cellular and humoral antifilarial immune responses in three groups of patients : i) those who were antigen and microfilaria negative, ii) those who were antigen positive and microfilaria negative, and iii) those who were antigen and microfilaria positive. The authors demonstrated that there were strong associations between the absence of circulating antigen levels, Th-1 like responses (especially filarial 
antigen induced IL-2 levels), and antigen induced proliferation of PBMCs. Filarial antigen-induced proliferation of PBMCs correlated with the absence of filarial specific circulating antigens accompanied by a Thl like response. Similar results were reported in patients with elephantiasis and lymphoedema (Addiss et al., 1995) indicating that increase in filarial antigen induced proliferation of the PBMCs correlated with the absence of circulating antigens. The authors demonstrated that significantly elevated antifilarial IgG4 levels were associated with antigenemia, whereas microfilaraemia was associated with significantly decreased antifilarial IgG2 levels.

BmA-specific lymphocyte responses in the MFs treated with DEC in this study were accompanied by rapid clearance of microfilariae (Fig 2a). DEC is known to produce alterations in the microfilarial surface membranes, thereby rendering them more susceptible to destruction by host defence mechanisms (Hawking, 1979; Mackenzie and Kron, 1985). The drug unmasks the microfilariae which are covered by host molecules and might release antigens which may be presented to the $T$ cells and result in an increased $\mathrm{T}$ cell proliferative response. The persistence of filarial specific circulating antigens in these individuals might be the reason for the relatively decreased BmAspecific lymphocyte response observed on days seven and fourteen after start of chemotherapy (Fig 3). The lymphocyte proliferative responses seen on day seven of treatment was higher than pre-treatment levels, but they were not statistically significant ( $>0.05)$. Dimock et al. (1996) have shown that individuals differ in their lymphocyte responsiveness to adult filarial antigens based on microfilarial status. Further, they have 
extended these observations by showing that increased proliferative responses to adult antigens are associated with the absence of filarial specific circulating antigens. The presence of circulating antigens may shift the host immune responses to Th2 type.

In filariasis, MFs exhibit Th2-like $T$ cell response whereas $\mathrm{CPs}$ exhibit Th1-like $\mathrm{T}$ cell response (King et al., 1993). It has also been shown that MFs produce increased levels of IL-10 in vitro in response to filarial parasite antigens (Mahanty et al., 1996) when compared with CPs and ENs. The role of IL-10, however, is not clearly defined. Addition of monoclonal antibodies to IL-10, to in vitro cell cultures of PBMCs from MFs restores the ability of their celis to proliferate and subsequently result in the production of Thl type cytokines (Pearlman et al., 1993). Mahanty et al. (1993) have demonstrated that filarial antigens selectively stimulate IL-4 and IL-5 production in MFs. Earlier reports by Sartono et al. (1995) have demonstrated elevated cellular immune responses and increased production of IFN-y in different clinical groups after long term chemotherapy with DEC.

In the current study we attempted to characterise the cellular immune response of the MFs during the recommended period of chemotherapy with DEC. PBMCs from three MFs were evaluated for unstimulated as well as BmA driven expression of the cytokine genes IL-2 and IL-10 before and on day 7 during DEC treatment.

In the unstimulated PBMCs, there was a significant increase in the expression of IL-2 $(p<0.05)$ on day 7 compared to pre-treatment levels. However, there was no significant 
increase $(p>0.05)$ in IL-2 levels in BmA stimulated PBMCs, on day 7 of DEC chemotherapy. One of the patients did not show any expression of BmA stimulated IL-2, although there was an expression of IL-2 in the unstimulated condition (Fig 4a). The reason for the absence of IL-2 expression in the BmA stimulated PBMCs in this patient could be an experimental error because the expression of HPRT and IL-10 genes by the PBMCs of this patient was normal (Fig 4a). As the number of individuals studied was too small, it is not possible to make any specific conclusions, especially regarding IL-2 levels in BmA stimulated PBMCs on day 7 of DEC treatment.

It is apparent from the current in vitro studies that there is an increase in IL-2 expression in unstimulated PBMCs on the seventh day of DEC chemotherapy suggesting that IL-2 secretion by the $\mathrm{T}$ lymphocytes is stimulated. Since IL-2 is the principle cytokine responsible for $\mathrm{T}$ cell proliferation, it was not surprising that IL-2 secretion correlated with the increased lymphocyte proliferative response seen on the seventh day compared to pre-treatment levels (Figs $4 \mathrm{a}$ and $\mathrm{b}$ ).

DEC treatment also resulted in significantly increased production of IL- 10 in BmA stimulated cultures on day 7 of chemotherapy compared to pre treatment levels $(p<0.05)$ (Figs $4 \mathrm{a}$ and $\mathrm{b}$ ). However, the increase in the levels of $\mathrm{IL}-10$ in unstimulated PBMCs seen on day 7 of DEC treatment compared to pre treatment levels was not statistically significant ( $p>0.05$ ). In addition to $T$ lymphocytes, the known cellular sources of $\mathbb{L}-10$ are macrophages, keratinocytes, and B lymphocytes. IL-10 inhibits the production of proinflammatory cytokines by monocytes and macrophages (Liles and Voorhis, 1995). 
Since IL-2 is produced exclusively by $\mathrm{T}$ lymphocytes, perhaps the effect of IL-10 on T cell secretion of IL-2 is minimal. Clearance of microfilariae by DEC in the host may result in stimulation of $\mathrm{T}$ cells to produce IL-2 and IL-10 (cytokines that may be useful for both $\mathrm{T}$ cell proliferation as well as maintenance of hyporesponsiveness). It is known that IL-10, alongwith IL-4 and IL-5 stimulates the production of basophils, mast cells and eosinophils (Moore et al., 1993). Increased levels of IL-10 by unstimulated PBMCs seen on the seventh day after treatment may influence the levels of eosinophils seen during chemotherapy.

In the current study we have not investigated the cytokine profiles of CPs and ENs preand post-chemotherapy with DEC because DEC is of very little help to CPs who exhibit advanced lymphatic pathology. Further, Freedman et al. (1995) have reported that DEC treatment does not have any demonstrable direct or indirect effect on the dilated lymphatics and the abnormalities observed in CPs. ENs are often non compliant in drug treatment when they lack both circulating microfilariae and clinical symptoms and are difficult to treat and study.

The changes in antigen driven- $T$ cell proliferation and cytokine expression 3-14 months after therapy have been studied in other helminth parasitic infections such as Schistosomiasis and Onchocerciasis. Such studies showed a significant increase in T cell proliferation driven by parasite antigens in both the infections following therapy (Soboslay et al., 1992; Colley et al., 1986; Steel et al., 1991). Cytokine patterns indicated that IFN- $\gamma$ and IL-2 production increased significantly in Schistosomiasis, but 
no such change in parasite antigen specific production of IL-2, IFN- $\gamma$ and IL-4 occurred in Onchocerciasis following therapy (Soboslay et al., 1992).

The hyporesponsiveness / T cell anergy that is maintained in the MFs may be attributed to the increased levels of antifilarial IgG4 subclass antibodies present exclusively in this group (Bulletin of WHO, 1993). This class of blocking antibodies are considered protective in MFs as they selectively block specific IgE mediated inflammatory responses. To resolve the role played by these antibodies, it is essential that the infection is eliminated by chemotherapy and consequent changes in the antibody responses followed.

DEC clears circulating microfilariae (Fig 2a) and restores the BmA-specific proliferation of the PBMCs (Fig 3), after one day of treatment. We studied the levels of the BmAspecific antibodies before and during DEC treatment. When compared to pre-treatment levels, there were no statistically significant differences in the mean OD values of $\mathrm{BmA}$ specific isotype antibody levels following DEC treatment ( $p>0.05$ ) (Fig $5 a$ and $b)$. The possible reason could be attributed to the fact that the period of time chosen for investigating the changes was too short.

Maizels et al. (1995) in their review have reported the findings by Kurniawan et al., who after following a long term low dose DEC therapy (100mg per week), have evaluated the isotype antibody levels after one year. They have demonstrated that the antibody levels generally fall by one year after DEC treatment. Antifilarial IgG4 levels which correlate 
significantly with microfilarial counts, dropped expeditiously than IgGl levels, with no changes in the titres of IgG2 and IgG3 isotypes by one year following chemotherapy. In the current study, however, we are unable to show any statistically significant differences in BmA-specific isotype antibody levels following chemotherapy (Fig 5a). Morphological changes that DEC induces in microfilariae renders them more susceptible to destruction by host phagocytes (Hawking, 1979; Mackenzie and Kron, 1985). Filarial specific antibodies were probably being made but constantly neutralised by soluble antigens released by dying microfilariae following chemotherapy. DEC does not kill microfilariae in vitro suggesting that phagocytic destruction of microfilariae occurs only after immunity has been established.

An important feature of filariasis like with other helminth infections is the potent IgE responses from their host. Hussain et al. (1981) and Hussain and Ottesen (1983) have demonstrated both qualitatively and quantitatively the distinct differences in the IgE responses of the various clinical groups of patients. IgE levels were high among all clinical groups but allergic symptoms were manifested by only a minority of individuals who exhibited TPE. IgG4 levels may account for the modulation of IgE levels because IgG4 antibodies have been implicated as the "blocking antibodies" responsible for controlling $\operatorname{lgE}$ mediated allergic responsiveness either by competing with cell bound IgE for specific allergens, or by inhibiting the binding of IgE molecules to cell surface receptors on mast cells or basophils (Ottesen et al., 1985). In human lymphatic filariasis, IgG4 responses parallel IgE responses (Hussain and Ottesen, 1986) perhaps because both 
IgE and IgG4 depend upon $\mathbb{I}-4$ as a differentiation stimulus (Lundgren et al., 1989; Ishizaka et al., 1990). Kurniawan et al. (1993) reported that active infection seen in MFs may promote parasite specific IgG4 antibodies, and limit IgE levels. The circumstances under which IgE secretion may be blocked without inhibition of IgG4 in human lymphatic filariasis is obscure. We evaluated simultaneously the BmA-specific IgE and IgG4 responses in the MFs, pre- and post-treatment period. Post DEC treated levels of BmA-specific IgE did not differ significantly from pre-treatment levels ( $p>0.05$ ) (Fig 5b).

The appearance of serum antimicrofilarial IgM has been correlated with the clearance of microfilariae from the blood circulation in mice (Thompson et al., 1981), but our study indicated no such statistically significant relationship by the end of the treatment period (Fig 5b).

Blood neutrophil numbers increased significantly $(p<0.01)$ on the first day of DEC treatment in the MFs (Fig 6). This corresponded to the clearance of microfilaria from the peripheral blood. Neutrophils, being the first form of defence might mediate clearance of microfilaria from circulation.

Eosinophil counts significantly increased $(p<0.05)$ on day 7 after start of treatment and declined by day 14 (Fig 6). Limaye et al. (1993) determined that serum IL-5 levels were related to eosinophil counts in MFs receiving DEC treatment (given at a dosage of 300 $\mathrm{mg} /$ day orally for 12 days). Our findings agree with Limaye et al. (1993) who found that eosinophil counts reached a peak at day 7 after start of treatment and declined by day 14 . Antibody-dependent eosinophil killing was well studied using in vitro models of 



\section{CONCLUSIONS}

1. BmA-specific PBMC proliferative responses in MFs increased one day after initiating DEC therapy.

2. Expression of $\mathbb{L}-2$ and IL-10 cytokines in MFs increased on day seven after initiating DEC therapy.

3. Circulating neutrophil and eosinophil numbers increased after DEC treatment suggesting their involvement in mediating parasite clearance.

4. Microfilariae were cleared by one day after DEC treatment indicating that microfilariae are susceptible to DEC treatment. No significant reduction in the levels of filarial specific circulating antigens were observed.

5. No statistically significant changes were observed in filarial specific antibody levels during the treatment period indicating either the period of time chosen to investigate such levels was too short or antibodies were constantly made and neutralised by soluble antigens released by dying microfilariae. 


\section{REFERENCES}

Addiss, D.G., K.D. Dimock, M.L. Eberhard, and P.J. Lammie. 1995. Clinical. parasitologic, and immunologic observations of patients with hydrocele and elephantiasis in an area with endemic lymphatic filariasis. J. Infect. Dis. 171:755-758.

Allen, J. E., and M. Rick Maizels. 1996. Immunology of human helminth infection. Int. Arch. Allergy Immunol. 109:3-10.

Amaral, F., G. Dreyer, J. Figueredo-Silva, J. Noroes, A. Cavalcanti, S.C. Samico, A. Santos, and A. Coutinho. 1994. Live adult worms detected by ultrasonography in human Bancroftian filariasis. Am. J. Trop. Med. Hyg. 50:753-757.

Auriault, C., M.A. Ouaissi, G. Torpier, H. Eisen, and A Capron. 1981. Proteolytic cleavage of IgG bound to the Fc receptor of Schistosoma mansoni schistosomula. Parasite Immunol. 3:33-44.

Bodgan, C., Y. Vodovotz, and C. Nathan. 1991. Macrophage deactivation by interleukin-10. J. Exp. Med. 174:1549-1555.

Boyum, A. 1968. Separation of leukocytes from blood and bone marrow. Scand. J. Clin. Lab. Invest. 21:77-89.

Bulletin of the WHO. 1993. Lymphatic filariasis: diagnosis and pathogenesis. 71:135141.

Chanteau, S., J.P. Moulia-pelat, P. Glaziou, N.L. Nguyen, P. Luquiaud, C. Plichart, P.M.V. Martin, and J.L. Cartel. 1994. Og4C3 Circulating Antigen: A Marker of Infection of Adult Worm Burden in Wuchereria bancrofti Filariasis. J. Infect. Dis. 170:247-250.

Chomczynski, P., and N. Sacchi. 1987. Single step method of RNA isolation by acid guanidium thiocyanate phenol-chloroform extraction. Anal. Biochem. 162:156-159.

Clemens, M.J. 1991. Introduction to Cytokines, p.7-21. In P.R. Andrew and T. Brown. (ed.), Cytokines. BIOS Scientific Publishers Limited, Oxford, OXI 1SJ.

Colley, D.G., I.S. Barsoum, H.S.S. Dahawi, F. Gamil, M. Habib, and M.A. El Almamy. 1986. Immune responses and immunoregulation in relation to Human Schistosomiasis in Egypt III. Immunity and Longitudinal Studies of in vitro responsiveness after Treatment. Trans. R. Soc. Trop. Med. Hyg. 80:952-957. 
Denham, D.A., and P.B. McGreevy. 1977. Brugian filariasis. Adv. Parasitol. 17:243308.

Dhanda, V., P.K. Das, R. Lal, R. Srinivasan, and K.D. Ramaiah. 1996. Spread of lymphatic filariasis, re-emergence of leishmaniasis \& threat of babesiosis in India. Indian. J. Med. Res. 103:46-54.

Diallo, S., M.A. Aziz, M. Lariviere, J.S. Diallo, I. Diop-Mar, O. N'Dir, S. Badiane, D. Py, H. Schutz-Key, P. Gaxotte, and A. Victorius. 1986. A double blind comparison of the efficacy and safety of ivermectin and diethylcarbamazine in a placebo controlled study of Senegalese patients with onchocerciasis. Trans. R. Soc. Trop. Med. Hyg. 80:927-934.

Dimock, K.A., D.G. Addis, M.L. Eberhard, and P.J. Lammie. 1994. Differential proliferative and interleukin 10 responses to fractionated filarial antigens: preferential recognition by patients with chronic lymphatic dysfunction. J. Infect. Dis. 170:403-412.

Dimock, K.A., M.L. Eberhard, and P.J. Lammie. 1996. Th-1 Like Antifilarial Immune Responses Predominate in Antigen-Negative Persons. Infect. Immun. 64:2962-2967.

Dissayanake, S., H. Zheng, G. Dreyer, M. Xu, L. Watawana, G. Cheng, S. Wang, P. Morin, B. Deng, L. Kurniawan, A. Vincent, and W.F. Piessens. 1994. Evaluation of a recombinant parasite antigen for the diagnosis of lymphatic filariasis. Am. J. Trop. Med. Hyg. 50:727-734.

Dissanayake, S., L. Watawana, and W.F. Piessens. 1995. Lymphatic pathology in Wuchereria bancrofti microfilaraemic infections. Trans. R. Soc. Trop. Med. Hyg. 89:517521.

Dreyer, G., F. Amaral, J. Noroes, and Z. Medeiros. 1994 (a). Lltrasonographic evidence for stability of adult worm location in Bancroftian filariasis. Trans. R. Soc. Trop. Med. Hyg. 88:558.

Dreyer, G., M.L. Pires, L.D. de Andrade, E. Lopes, Z. Medeiros, J. Tenoria, A. Coutinho, J. Noroes, and J. Figueredo- Silva. 1994 (b). Tolerance of diethylcarbamazine by microfilaraemic and amicrofilaraemic individuals in an endemic area of Bancroftian filariasis, Recife, Brazil. Trans. R. Soc. Trop. Med. Hyg. 88:232-236.

Dreyer, G., F. Amaral, J. Noroes, Z. Medeiros, and D. Addiss. 1995. A new tool to assess the adulticidal efficacy in vivo of antifilarial drugs for bancroftian filariasis. Trans. R. Soc. Trop. Med. Hyg. 89:225-226.

Duke, B. O. L. 1980 . Problems of chemotherapy with diethylcarbamazine citrate in lymphatic filariasis. WHO/FIL Series. 158:1-9. 
Eberhard, M. L., and P.J. Lammie. 1991. Laboratory Diagnosis of Filariasis. Clinics in Laboratory Medicine. 11:977-1010.

Fiorentino, D. F., M.W. Bond, and T.R. Mossman. 1989. Two types of helper T cell. IV. Th-2 clones secrete a factor that inhibits cytokine production by Thl clones. J. Exp. Med. 170:2081-2095.

Franks, M. B. 1946. Specific soluble antigen in the blood of filarial patients. J. Parasitol. 32:400-406.

Freedman, O.D., T. Bui, P.J. de Almeida Filho, C. Bragfa, M. Carmelita, M.E. Silva, A. Maciel, and A.F. Furtado. 1995. Lymphoscintigraphic Assessment of the Effect of Diethylcarbamazine Treatment on Lymphatic Damage in Human Bancroftian Filariasis. Am. J. Trop. Med. Hyg. 52:258-261.

Gazzinelli, R.T., I.P. Oswald, and S.L. James. 1992. IL-10 inhibits parasite killing and nitrogen oxide production by IFN-gamma activated macrophages. J. Immunol. 148:17921796.

Greene, B.M., H.R. Taylor, E.W. Cupp, R.P. Murphy, A.T. White, M.A. Aziz, H. Schulz-Key, S.A. D'Anna, H.S. Newland, L.P. Goldschmidt, C. Auer, A.P. Hanson, V. Freeman, E.W. Reber, and P.N. Williams. 1985. Comparison of ivermectin and diethylcarbamazine in the treatment of onchocerciasis. New Eng. J. Med. 313:133-138.

Hagan, P., J.B. Ursula, D. Dunn, J.G. Andrew Simpson, and H. Andrew Wilkins. 1991. Human IgE, IgG4 and resistance to reinfection with Schistosoma haematobium. Nature. 349:243-245.

Hawking, F. 1979. DEC and new compounds for the treatment of filariasis. Adv. Pharmacol. Chemother. 6:129-194.

Hewitt, R. I., E. White, W.S. Wallace, H.W. Steward, S. Kushner, and Y. SubbaRow. 1947. Experimental chemotherapy on filariasis. II. Effect of piperazine derivatives against naturally acquired filarial infections in cotton rats and dogs. J. Lab Clin. Med. 32:13041313.

Hussain, R., R.G. Hamilton, V. Kumaraswami, N.F. Adkinson, and E.A. Ottesen. 1981. IgE responses in human filariasis. I. Quantitaton of filaria-specific IgE. J. Immunol. 127:1623-1629.

Hussain, R., and E.A. Ottesen. 1983. IgE responses in human filariasis. II. Qualitative characterization of filaria-specific IgE. J. Immunol. 127:1623. 
Hussain, R., and E. A. Ottesen. 1986. IgE responses in human filariasis. IV. Parallel antigen recogniction by IgE and IgG4 subclass antibodies. J. Immunol. 136:1859.

Ishizaka, A., Y. Sakiyama, M. Nakanishi, K. Tomizawa, E. Oshika, K. Kojima, Y. Taguchi, E. Kandil, and S. Matsumoto. 1990. The inductive effect of interleukin-4 on IgG4 and IgE synthesis in human peripheral blood lymphocytes. Clin. Exp. Immunol. 79:392-397.

Jenkins, D.C. 1990. Ivermectin in the treatment of filarial and other nematode infections of man. Trop. Dis. Bull. 87:R1-R9.

Kim, J.M., C.I. Brannan, and N.G. Copeland. 1992. Structure of the mouse interleukin10 gene and chromosomal localization of the mouse and human genes. J. Immunol. 148:3618-3623.

King, C.L., and T.B. Nutman. 1991. Regulation of the immune response in lymphatic filariasis and onchocerciasis. Immunol. Today. 12:A54-A58.

King, C.L., V. Kumaraswamy, T. Poindexter, S. Kumari, K. Jayaraman, D.W. Allind, E.A. Ottesen, and T.B. Nutman. 1992. Immunological tolerance in Lymphatic filariasis: Diminished parasite specific $\mathrm{T}$ and $\mathrm{B}$ lymphocyte precursor frequency in microfilaraemic state. J.Clin.Invest. 89:1403-1410.

King, C.L., S. Mahanty, V. Kumaraswami, J.S. Abrams, J. Regunathan, K. Jayaraman, E.A. Ottesen, and T.B. Nutman. 1993. Cytokine control of ParasiteSpecific Anergy in Human Lymphatic Filariasis: Preferential Induction of a Regulatory T Helper Type 2 Lymphocyte Subset. J. Clin. Invest. 92: 1667-1673.

Kurniawan, A., M. Yazdanbaksh, R. van Ree, R. Aalberse, M.E. Selkirk, F. Partono and R.M. Maizels. 1993. Differential expression of IgE and IgG4 specific antibody responses in asymptomatic and chronic human filariasis. J. Immunol. 150:3941-3950.

Lal, R.B., and E.A. Ottesen. 1988. Enhanced Diagnostic Specificity in human filariasis by IgG4 antibody assessment. J. Infect. Dis. 158:1034-1037.

Lamb, J.R., B.J. Skidmore, N. Green, J.M. Chiller, and M. Feldmann. 1983. Induction of tolerance in influenza virus-immune $\mathrm{T}$ lymphocyte clone with synthetic peptides of influenza hemagglutinin. J. Exp. Med. 157:1434-1447.

Lammie, P.J., L. Eberhard, L.E. Leiva, R.C. Lowrie, and S.P. Katz. 1988. The effect of diethylcarbamazine treatment in Bancroftian filariasis on immunological reactivity of microfilaraemic individuals. Trans. R. Soc. Trop. Med. Hyg. 82:726-729. 
Langham, M.E., and T.R. Kramer. 1980. The in vitro effect of DEC on the mobility and survival of Onchocerciasis volvulus microfilariae. Tropen Med. Parasitology. 31:59-66.

Lasalle, J.M., and D.A. Hafler. 1994. T cell anergy. FASEB Journal. 8:601-608.

Lawrence, R.A., and D.A. Denham. 1993. Stage and isotype specific immune responses in a rat model of filariasis. Parasite Immunol. 15:429-439.

Leeuwin, R.S. 1962. Microfilaraemia in Surinamese living in Amsterdam. Trop. Geogr. Med. 14:355-360.

Leiva, L.E., and P.J. Lammie. 1989. Modulation of lymphocyte activation by soluble Brugia pahangi extracts. Trop. med. Parasitol. 40:327-331.

Liles, C.W., and W.C. van Voorhis. 1995. Review: Nomenclature and Biological Significance of Cytokines Involved in Inflammation and the Host Immune Response. J. Infect. Dis. 172:1573-1580.

Limaye, A.P., E.A. Ottesen, V. Kumaraswami, J.S. Abrams, J. Regunathan, V. Vijayasekaran, K. Jayaraman, and T.B. Nutman. 1993. Kinetics of Serum and Cellular Interleukin-5 in Posttreatment Eosinophilia of Patients with Lymphatic Filariasis. J. Infect. Dis. 167:1396-1400.

Liu, L.X., C.N. Serhan, and P.F. Weller. 1990. Intravascular filarial parasites elaborate cyclo oxygenase-derived eicosanoids. J. Exp. Med. 172:993-996.

Lundgren, M., U. Persson, P. Larsson, C. Magnusson, C.I.E. Smith, L. Hammarstrom, and E. Severninson. 1989. Interleukin 4 induces cytokine synthesis of IgE and IgG4 in human B cells. Eur. J. Immunol. 19:1311-1315.

Mackenzie, C.D., and M.A. Kron. 1985. DEC: a review of its action in Onchocerciasis, Lymphatic filariasis and inflammation. Trop. Dis. Bull. 82:R1-R37.

Mahanty, S., C.L. King, V. Kumaraswami, J. Regunathan, A. Maya, K. Jayaraman, J.S. Abrams, E.A. Ottessen, and T.B. Nutman. 1993. IL-4 and IL 5 secreting lymphocyte populations are preferentially stimulated by parasite-derived antigens in human tissue invasive nematode infections. J. Immunol. 151:3704-3711.

Mahanty, S., S.N. Mollis, M. Ravichandran, J.S. Abrams, V. Kumaraswami, K. Jayaraman, E.A Ottesen, and T.B. Nutman. 1996. High levels of spontaneous and parasite antigen driven $\mathbb{L}-10$ are associated with antigen specific hyporesponsiveness in human lymphatic filariasis. J. Infect. Dis. 173:769-774. 
Maniatis, T., E.F. Fritsch, and J. Sambrook. 1989. Molecular Cloning: a laboratory manual. Cold Spring Harbor Laboratory, Cold Spring Harbor, NY.

Maizels, R.M., A. Kurniawan, M.E. Selkirk, and M. Yazdanbakhsh. 1991. Immune responses to filarial parasites. Immunology Letters. 30:249-254.

Maizels, R.M., D.A.P. Bundy, M.E. Selkirk, D.F. Smith, and R.M. Anderson. 1993. Immunological modulation and evasion by helminth parasites in human populations. Nature. 365:797-805.

Maizels, R.M., E. Sartono, A. Kurniawan, F. Partono, M.E. Selkirk, and M. Yazdanbakhsh. 1995. T-cell Activation and the Balance of Antibody Isotypes in Human Lymphatic Filariasis. Parasitology Today. 11:50-56.

Malefyt, de Waal R., J. Adams, and B. Bennett. 1991 (a). Interleukin-10 (IL-10) inhibits cytokine synthesis by human monocytes: an autoregulatory role of IL-10 produced by monocytes. J. Exp. Med. 174:1209-1220.

Malefyt, de Waal R., J. Haanen, H. Spits, M.G. Roncarolo, V.C. Figdor, K. Johnson, R. Kastelein, H. Yssel, and J.E. de vries. 199 l (b). Interleukin 10 (IL-10) and viral IL-10 strongly reduce antigen-specific human $\mathrm{T}$-cell proliferation by diminishing the antigenpresenting capacity of monocytes via down regulation of class II major histocampatability complex expression. J. Exp. Med. 174:915-924.

Mataika, J.U., E. Kimura, J. Koroivueta, Kaisuva, M. Brown, J. Tuivaga, S. Bikai, and S.R. Govind. 1993. Comparison of the Efficacy of Diethylcarbamazine Between 5 Rounds of Annual Single Dose Treatment and an Intensive 28 Dose Treatment Spread over 2 years Against Diurnally subperiodic Wuchereria bancrofii in Fiji. Fiji. Med. J. 19:2-6.

McCarthy, S.J., A. Guinea, G.J. Weil, and E.A. Ottesen. 1995. Clearance of Circulating Filarial Antigen as a Measure of the Macrofilaricidal Activity of Diethylcarbamazine in Wuchereria bancrofti Infection. J. Infect. Dis. 172:521-526.

Modlin, L.R., and T.B. Nutman. 1993. Type 2 cytokines and negative immune regulation in human infections. Current Opinion in Immunology. 5:511-517.

Moore, W.K., A. O'Garra, R. de Waal Malefyt, P. Vieira, and T.R. Mosmann. 1993. Interleukin-10. Ann. Rev. Immunol. 11:165-190.

Moore, W.K., S. Alice, Y. Ho, and J. Xu-Amano. 1995. Molecular Biology of Interleukin-10 and its receptor, p.1-8. In J. E. de Vries and Rene de Wall Malefyt (ed.), Interleukin-10. DNAX Research Institute, Department of Human Immunology, Palo Alto, CA. R.G. Landes Company, Austin, TX. 
More, S.J., and D.B. Copeman. 1990. A highly specific and sensitive monoclonal antibody based ELISA for the detection of circulating antigen in bancroftian filariasis. Trop. Med. Parasitol. 41:403-406.

Mossman, T.R., and R.L. Cofiman. 1989. Th1 and Th2 cells: different pattern of lymphokine secretion lead to different functional properties. Ann. Rev. Immunol. 7:145173.

Nanduri, J., and J.W. Kazura. 1989. Clinical and Laboratory Aspects of Filariasis. Clinical Microbiology Reviews. 21:39-50.

Nutman, T.B., V. Kumaraswami, and E.A. Ottesen. 1987. Parasite-specific anergy in human filariasis. Insights after analysis of parasite antigen-driven lymphokine production. J. Clin. Invest. 79:1516-1523.

Ottesen, E.A., P.F. Weller, and L. Heck. 1977. Specific cellular immune unresponsiveness in human filariasis. Immunology. 33:413-421.

Ottesen, E.A., V. Kumaraswami, R. Paranjape, R.W. Poindexter, and S.P. Tripathy. 1981. Naturally occuring blocking antibodies modulate immediate hypersensitivity responses in human filariasis. J. Immunol. 127:2014-2020.

Ottesen, E.A. 1985. Efficacy of Diethylcarbamazine in Eradicating Infection with Lymphatic-Dwelling Filariae in Humans. Reviews of Infectious Diseases. 7:341-356.

Ottesen, E.A., F. Skvaril, S.P. Tripathy, R.W. Poindexter, and R. Hussain. 1985. Prominence of IgG4 in the IgG Antibody Response to Human Filariasis. J. Immunol. 134:2707-2712.

Ottesen, E.A. 1994. The Human filariasis: new understandings, new therapeutic strategies. Current Opinion in Infectious diseases. 7:550-558.

Peariman, E., F.E. Hazlett, W. Henry Boom, and J.W. Kazura. 1993. Induction of murine $T$ helper responses to filarial nematode Brugia malayi. Infect. Immun. 61:11051112.

Piessens, F.W., P.B. McGreevy, S. Ratiwayanto, M. McGreevy, P.W. Piessens, I. Koiman, S. Saroso, Jr., and D.T. Dennis. 1980 (a). Immune responses in human infections with Brugia malayi: correlation of cellular and humoral reactions to microfilarial antigens with clinical status. Am. J. Trop. Med. Hyg. 31:953-957. 
Piessens, W.F., S. Ratiwayanto, S. Tuti, J.H. Palmieri, P.W. Piessens, I. Koiman, and D.T. Dennis. 1980 (b). Antigen Specific Suppressor Cells and Suppressor Factors in Human Filariasis with Brugia malayi. New Eng. J. Med. 302:833-836.

Pritchard, D.I. 1993. Immunity to helminths: is too much IgE parasite- rather than hostprotective?. Parasite Immunol. 15:5-9.

Ravichandran, M. 1996. Ph.D. thesis. Anna University, Chennai, India.

Ravichandran, M., S. Mahanty, V. Kumaraswami, T.B. Nutman, and K. Jayaraman. 1997. Elevated IL 10 mRNA expression and downregulation of Th1 type cytokines in microfilaremic individuals with Wuchereria bancrofti infection. (In Press, Parasite Immunol.).

Regunathan, J. 1996. Ph.D. thesis. Anna University, Chennai, India.

Regunathan, J., K. Jayaraman, and P. Kaliraj. 1997. Cellular immune response studies in bancroftian filariasis. (In Press, J. Helminthology).

Sartrono, E., Y.C.M. Kruize, A. Kurniawan, P.H. van der Meide, F. Partono, R.M. Maizels, and M. Yazdanbakhsh. 1995. Elevated Cellular Immune Responses and Interferon- $\gamma$ Release after Long-Term Diethylcarbamazine Treatment of Patients with Human Lymphatic Filariasis. J. Infect. Dis. 171:1683-1687.

Simmons, A. 1989. Haemotology: A Combined theoretical and technical approach. p.214-219. WB Sanders Company, Harcourt Brace Johnson, Inc. Philadelphia. PA.

Soboslay, P.T., C.M. Dreweck, W.H. Hoffman, D.G.K. Luder, C. Heuschkel, H. Gorgen, M. Bania, and H. Schulzkey. 1992. Ivermectin facilitated immunity in Onchocerciasis. Reversal of Lymphocytopenia, Cellular Anergy and Deficient Cytokine production after single treatment. Clin Exp Immunol. 89:407-413.

Steel, C., T.A. Lujan, P.C. Gonzalez, F.G. Zea, and T.B. Nutman. 1991. Immunologic responses to repeated Ivermectin treatment in patients with Onchocerciasis. J. Infect. Dis. 164:581-587.

Steel, C., A. Guinea, J. McCarthy, and E.A. Ottesen. 1994. Long term effect of prenatal exposure to maternal microfilaraemia on immune responsiveness to filarial parasite antigens. Lancet. 343:890-893.

Sutton, B.J., and H.J. Gould. 1993. The human IgE network. Nature. 366:421-428. 
Thompson, J.P., R.B. Crandall, C.A. Crandall, and J.T. Neilson. 1981. Microfilaraemia and antibody responses in CBA/H and CBA/N mice following injection of microfilariae of Brugia malayi. J. Parasitol. 67:728.

Turner, F.P., K.A. Rockett, E.A. Ottesen, H. Francis, K. Awadzi, and I.A. Clark. 1994. Interleukin-6 and Tumor Necrosis Factor in the Pathogenesis of Adverse Reactions after Treatment of Lymphatic Filariasis and Onchocerciasis. J. Infect. Dis. 169:1071-1075.

Urban, J., I.M. Katona, W.M. Paul, and R.D. Finkelman. 1991. Interleukin-4 is important in protective immunity to a gastrointestinal nematode infection in mice. Proc. Natl. Acad. Sci. USA. 88:5513-5517.

Urban, J., K.B. Madden, A. Svetic, A. Cheever, P.P Trotta, W.C. Gause, I.M. Katona, and F.D. Finkelman. 1992. The importance of Th2 cytokines in protective immunity to nematodes. Immunol. Rev. 127:205-254.

WHO Expert Committee Meeting on Filariasis. 1992. Lymphatic Filariasis: The disease and its control. World Health Organ Tech Rep Ser 821:77 .

WHO/CTD/TDR. 1994. Lymphatic Filariasis Infection \& Disease: Control Strategies. Report of a WHO/CTD/TDR Consultative Meeting held at the Universiti Sains Malaysia. Penang, Malaysia.

Wang, C.C. 1984. Parasite Enzymes as Potential Targets for Antiparasitic Chemotherapy. Journal of Medicinal Chemistry. 27:1-9.

Watanabe, N., Y. Hayashi, A. Kobayashi, and H. Ohtomo. 1996. Brugia malayi infection in mice with selective suppression of IgE production. Int. Arch. Allergy. Immunol. 102:192-196.

Webster, L.T. Jr. 1992. Chemotherapy of Parasitic infections, p.954-977. In A.G. Gilman, T.W. Rall, A.S. Nies, P. Taylor (ed.), Goodmans and Gilman's The Pharmacological basis of therapeutics 8th ed. McGraw Hill, USA.

Weil, G.J., M.S. Malane, K.G. Powers, and L.S. Blair. 1985. Monoclonal antibodies to parasites antigens found in the serum of Dirofilaria immitis - infected dogs. J. Immunol. 134:1185-1191.

Weil, G.J., D.C. Jain, S. Santhanam, A. Malhotra, H. Kumar, K.V.P. Sethumadhavan, F. Liftis, and T.K. Ghosh. 1987. A Monoclonal Antibody-Based Enzyme Immunoassay for Detecting Parasite Antigenemia in Bancroftian Filariasis. J. Infect. Dis. 156:350-355. 
Weil, G.J., R. Chandrasekar, F. Liftis, C. McVay, S. Bosshardt, and T. Klei. 1990. Circulating parasite antigen in Brugia pahangi infected jirds. J. Parasitol. 76:78-84.

Weil, G.J., M.R. Reda Ramzy, R. Chandrasekar, M. Adel Cad, C. Robert Lowrie Jr., and R. Faris. 1996. Parasite antigenemia without microfilaremia in bancroftian filariasis. Am. J. Trop. Med. Hyg. 55:333-337.

Wilson, A.R. 1993. Immunity and immunoregulation in helminth infections. Current Opinions in Immunology. 5:538-547.

Yazdanbakhsh, M., W.A. Paxton, Y.C.M. Kruize, E. Sartono, A. Kurniawan, A. van het Wout, M.E. Selkirk, F. Partono, and R.M. Maizels. 1993. T cell responsiveness correlates differentially with antibody isotype levels in Clinical and aymptomatic filariasis. J. Infect. Dis. 167:925-931.

Zheng, H., W.F. Piessens, Z. Tao, W. Chen, S. Wang, S. Chen, Y. Ye, L. Luo, X. Chen, and G. Gan. 1991. Efficacy of ivermectin for control of microfilaremia recurring after treatment with diethylcarbamazine I. Clinical and parasitological observations. Am. J. Trop. Med. Hyg. 45:168-174. 


\section{APPENDIX I}

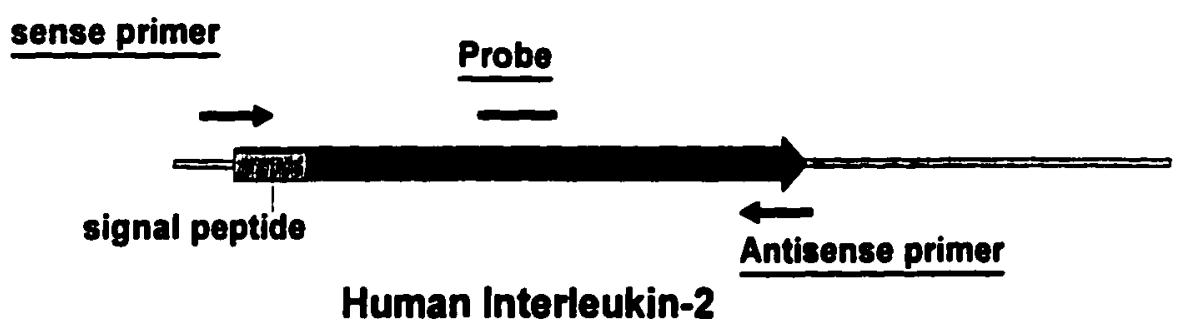

$801 \mathrm{bp}$

Genbank Accession Number V00564

IL-2 Sense primer ATG TAC AGG ATG CAA CTC CTG TCT T

IL-2 Anti sense primer GTC AGT GTT GAG ATG ATG CTT TGA C

IL-2 Probe GCC ACA GAA CTG AAA CAT CTT

1 ATCACTCTCTTTAATCACTACTCACAGTAACCTCAACTCCTGCCACAATG TAGTGAGAGAAATTAGTGATGAGTGTCATTGGAGTTGAGGACGGTGTTAC Sense primer

51 ACAGGATGCAACTCCTGTCTTGCATTGCACTAAGTCTTGCACTTGTCAC ATGTCCTACGTTGAGGACAGAACGTAACGTGATTCAGAACGTGAACAGTG

101 AAACAGTGCACCTACTTCAAGTTCTACAAAGAAAACACAGCTACAACTGG TTTGTCACGTGGATGAAGTTCAAGATGTTTCTTTTGTGTCGATGTTGACC

151 AGCATTTACTGCTGGATTTACAGATGATTTTGAATGGAATTAATAATTAC TCGTAAATGACGACCTAAATGTCTACTAAAACTTACCTTAATTATTAATG

201 AAGAATCCCAAACTCACCAGGATGCTCACATTTAAGTTTTACATGCCCAA TTCTTAGGGTTTGAGTGGTCCTACGAGTGTAAATTCAAAATGTACGGGTT Probe

251 GAAGGCCACAGAACTGAAACATCTTCAGTG TCTAGAAGAAGAACTCAAAC CTTCCGGTGTCTTGACTTTGTAGAAGTCACAGATCTTCTTCTTGAGTTTG 
301 CTCTGGAGGAAGTGCTAAATTTAGCTCAAAGCAAAAACTTTCACTTAAGA GAGACCTCCTTCACGATTTAAATCGAGTTTCGTTTTTGAAAGTGAATTCT

351 CCCAGGGACTTAATCAGCAATATCAACGTAATAGTTCTGGAACTAAAGGG GGGTCCCTGAATTAGTCGTTATAGTTGCATTATCAAGACCTTGATTTCCC

401 ATCTGAAACAACATTCATGTGTGAATATGCTGATGAGACAGCAACCATTG TAGACTTTGTTGTAAGTACACACTTATACGACTACTCTGTCGTTGGTAAC

451 TAGAATTTCTGAACAGATGGATTACCTTTTGTCAAAGCATCATCTCAACA ATCTTAAAGACTTGTCTACCTAATGGAAAACAGTTTCGTA GTAGAGTTGT Antisense primer

501 CTGACTTGATAATTAAGTGCTTCCCACTTAAAACATATCATTCCTTCTAT GACTGAACTATTAATTCACGAAGGGTGAATTTTGTATAGTAAGGAAGATA

551 TTATTTAAATATTTAAATTTTATATTTATTGTTGAATGTATGGTTTGCTA AATAAATTTATAAATTTAAAATATAAATAACAACTTACATACCAAACGAT

601 CCTATTGTAACTATTATTCTTAATCTTAAAACTATAAATATGGATCTTTT GGATAACATTGATAATAAGATTAGAATTTTGATATTTATACCTAGAAAA

651 ATCATTCTTTTTGTAAGCCCTAGGGGCTCTAAAATTGGTTTCACTTATTT TAGTAAGAAAAACATTCGGGATCCCCGAGATTTTAACCAAAGTGAATAAA

701 ATCCCAAAATATTTATTATTATGTTGAATGTTAAATATGTATCTATGTAG TAGGGTTTTATAAATAATAATACAACTTACAATTTATACATAGATACATC

751 ATTGGTTAGTAAAACTATTTAATAAATTTGATAAATATAAAAAAAAAAAA TAACCAATCATTTTGATAAATTATTTAAACTATTTATATTTTTTTTTTTT

801 C

G 


\section{APPENDIX II}

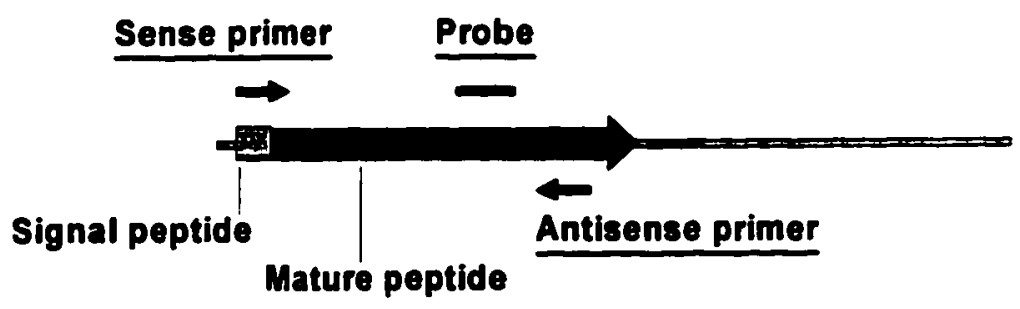

Human Interleukin-10

1601 bp

Genbank Accession Number M57627

IL-10 Sense primer ATG CAC AGC TCA GCA CTG CT

IL-10 Anti sense primer TCA GTT TCG TAT CTT CAT TGT CA

IL-10 Probe GCC ATG AGT GAG TTT GAC ATC

Sense primer

1 AAACCACAAG ACAGACTTGCAAAAGAAGGCATGCACAGCTCAGCACTGCT TTTGGTGTTCTGTCTGAACGTTTTCTTCCGTACGTGTCGAGTCGTGACGA

51 CTGTTGCCTGGTCCTCCTGACTGGGGTGAGGGCCAGCCCAGGCCAGGGCA GACAACGGACCAGGAGGACTGACCCCACTCCCGGTCGGGTCCGGTCCCGT

101 CCCAGTCTGAGAACAGCTGCACCCACTTCCCAGGCAACCTGCCTAACATG GGGTCAGACTCTTGTCGACGTGGGTGAAGGGTCCGTTGGACGGATTGTAC

151 CTTCGAGATCTCCGAGATGCCTTCAGCAGAGTGAAGACTTTCTTTCAAAT GAAGCTCTAGAGGCTCTACGGAAGTCGTCTCACTTCTGAAAGAAAGTTTA

201 GAAGGATCAGCTGGACAACTTGTTGTTAAAGGAGTCCTTGCTGGAGGACT CTTCCTAGTCGACCTGTTGAACAACAATTTCCTCAGGAACGACCTCCTGA 
251 TTAAGGGTTACCTGGGTTGCCAAGCCTTGTCTGAGATGATCCAGTTTTAC AATTCCCAATGGACCCAACGGTTCGGAACAGACTCTACTAGGTCAAAATG

301 CTGGAGGAGGTGATGCCCCAAGCTGAGAACAAGACCCAGACATCAAGGC GACCTCCTCCACTACGGGGTTCGACTCTTGGTTCTGGGTCTGTAGTTCCG

351 GCATGTGAACTCCCTGGGGGAGAACCTGAAGACCCTCAGGCTGAGGCTAC CGTACACTTGAGGGACCCCCTCTTGGACTTCTGGGAGTCCGACTCCGATG

401 GGCGCTGTCATCGATTTCTTCCCTGTGAAAACAAGAGCAAGGCCGTGGAG CCGCGACAGTAGCTAAAGAAGGGACACTTTTGTTCTCGTTCCGGCACCTC

451 CAGGTGAAGAATGCCTTTAATAAGCTCCAAGAGAAAGGCATCTACAAAGC GTCCACTTCTTACGGAAATTATTCGAGGTTCTCTTTCCGTAGATGTTTCG

\section{Probe}

501 CATGAGTGAGTTTGACATCTTCATCAACTACATAGAAGCCTACATGACAA GTACTCACTCAAACTGTAGAAGTAGTTGATGTATCTTCGGATGTACTGTT

551 TGAAGATACGAAACTGAGACATCAGGGTGGCGACTCTATAGACTCTAGGA ACTTCTATGCTTTGACTCTGTAGTCCCACCGCTGAGATATCTGAGATCCT Antisense primer

601 CATAAATTAGAGGTCTCCAAAATCGGATCTGGGGCTCTGGGATAGCTGAC GTATTTAATCTCCAGAGGTTTTAGCCTAGACCCCGAGACCCTATCGACTG

651 CCAGCCCCTTGAGAAACCTTATTGTACCTCTCTTATAGAATATTTATTAC GGTCGGGGAACTCTTTGGAATAACATGGAGAGAATATCTTATAAATAATG

701 CTCTGATACCTCAACCCCCATTTCTATTTATTTACTGAGCTTCTCTGTGA GAGACTATGGAGTTGGGGGTAAAGATAAATAAATGACTCGAAGAGACACT

751 ACGATTTAGAAAGAAGCCCAATATTATAATTTTTTTCAATATTTATTATT TGCTAAATCTTTCTTCGGGTTATAATATTAAAAAAAGTTATAAATAATAA

801 TTCACCTGTTTTTAAGCTGTTTCCATAGGGTGACACACTATGGTATTTGA AAGTGGACAAAAATTCGACAAAGGTATCCCACTGTGTGATACCATAAACT

851 GTGTTTTAAGATAAATTATAAGTTACATAAGGGAGGAAAAAAAATGTTCT CACAAAATTCTATTTAATATTCAATGTATTCCCTCCTTTTTTTTACAAGA

901 TTGGGGAGCCAACAGAAGCTTCCATTCCAAGCCTGACCACGCTTTCTAGC AACCCCTCGGTTGTCTTCGAAGGTAAGGTTCGGACTGGTGCGAAAGATCG

951 TGTTGAGCTGTTTTCCCTGACCTCCCTCTAATTTATCTTGTCTCTGGGCT ACAACTCGACAAAAGGGACTGGAGGGAGATTAAATAGAACAGAGACCCGA 
1001 TGGGGCTTCCTAACTGCTACAAATACTCTTAGGAAGAGAAACCAGGGAGC ACCCCGAAGGATTGACGATGTTTATGAGAATCCTTCTCTTTGGTCCCTCG

1051 CCCTTTGATGATTAATTCACCTTCCAGTGTCTCGGAGGGATTCCCCTAAC GGGAAACTACTAATTAAGTGGAAGGTCACAGAGCCTCCCTAAGGGGATTG

1101 CTCATTCCCCAACCACTTCATTCTTGAAAGCTGTGGCCAGCTTGTTATTT GAGTAAGGGGTTGGTGAAGTAAGAACTTTCGACACCGGTCGAACAATAAA

1151 ATAACAACCTAAATTTGGTTCTAGGCCGGGCGCGGTGGCTCACGCCTGTA TATTGTTGGATTTAAACCAAGATCCGGCCCGCGCCACCGAGTGCGGACAT

1201 ATCCCAGCACTTTGGGAGGCTGAGGCGGGTGGATCACTTGAGGTCAGGAG TAGGGTCGTGAAACCCTCCGACTCCGCCCACCTAGTGAACTCCAGTCCTC

1251 TTCCTAACCAGCCTGGTCAACATGGTGAAACCCCGTCTCTACTAAAAATA AAGGATTGGTCGGACCAGTTGTACCACTTTGGGGCAGAGATGATTTTTAT

1301 CAAAAATTAGCCGGGCATGGTGGCGCGCACCTGTAATCCCAGCTACTTGG GTTTTTAATCGGCCCGTACCACCGCGCGTGGACATTAGGGTCGATGAACC

1351 GAGGCTGAGGCAAGAGAATTGCTTGAACCCAGGAGATGGAAGTTGCAGTG CTCCGACTCCGTTCTCTTAACGAACTTGGGTCCTCTACCTTCAACGTCAC

1401 AGCTGATATCATGCCCCTGTACTCCAGCCTGGGTGACAGAGCAAGACTCT TCGACTATAGTACGGGGACATGAGGTCGGACCCACTGTCTCGTTCTGAGA

1451 GTCTCAAAAAAATAAAAATAAAAATAAATTTGGTTCTAATAGAACTCAGT CAGAGTTTTTTTATTTTTATTTTTATTTAAACCAAGATTATCTTGAGTCA

1501 TTTAACTAGAATTTATTCAATTCCTCTGGGAATGTTACATTGTTTGTCTO AAATTGATCTTAAATAAGTTAAGGAGACCCTTACAATGTAACAAACAGAC

1551 TCTTCATAGCAGATTTTAATTTTGAATAAATAAATGTATCTTATTCACAT AGAAGTATCGTCTAAAATTAAAACTTATTTATTTACATAGAATAAGTGTA

$1601 C$

G 